\title{
Gomphonema Ehrenberg e Gomphosphenia Lange-Bertalot (Bacillariophyceae) do Rio Maurício, Paraná, Brasil
}

\author{
Priscila Izabel Tremarin ${ }^{1,4}$, Lucielle Merlym Bertolli ${ }^{2}$, \\ Denise Matias de Faria ${ }^{2}$, Júlio César Costin² \& Thelma Alvim Veiga Ludwig ${ }^{3}$
}

\author{
${ }^{1}$ Departamento de Botânica, Universidade Federal do Rio Grande do Sul-UFRGS \\ Av. Bento Gonçalves, 9500, prédio 43433, CEP 91501-970, Porto Alegre, RS, Brazil, http://www.ufrgs.br \\ ${ }^{2}$ Programa de Pós-graduação em Botânica, Universidade Federal do Paraná - UFPR \\ ${ }^{3}$ Departamento de Botânica, Centro Politécnico, Universidade Federal do Paraná - UFPR, \\ CP 19031, CEP 81531-990, Jd. das Américas, Curitiba, PR, Brazil, http://www.ufpr.br/ \\ ${ }^{4}$ Autor para correspondência: Priscila Izabel Tremarin e-mail: ptremarin@ gmail.com
}

\begin{abstract}
TREMARIN, P.I., LUDWIG, T.A.V., BERTOLLI, L.M., FARIA, D.M. \& COSTIN, J.C. Gomphonema Ehrenberg and Gomphosphenia Lange-Bertalot (Bacillariophyceae) from Maurício river, Paraná, Brazil. Biota Neotrop., 9(4): http://www.biotaneotropica.org.br/v9n4/en/abstract?inventory+bn00309042009.
\end{abstract}

\begin{abstract}
The biogeography and morphological variability of Gomphonema and Gomphosphenia species are still poorly known in Brazil. Due to the secretion of mucilage by the apical pore fields, Gomphonema is a common genus in periphytic algal communities, being well represented in richness and density. Studied samples were removed from Potamogeton polygonus Chamess. \& Schltdl. and Egeria densa Planch. gathered in Maurício river, Fazenda Rio Grande, Paraná State. Twenty taxa were identified. Eleven species of Gomphonema and the genus Gomphosphenia were first recorded in the state of Paraná. In addition, the results of ultrastructural observations were presented. Variability in valve outline and ultrastructural details warrant further attempts to clarify the taxonomy of closely related species, such as: G. gracile and Gomphonema sp.5, G. contraturris and G. salae, G. capitatum and G. laticollum.
\end{abstract}

Keywords: diatoms, taxonomy, ultrastructure, lotic system.

TREMARIN, P.I., LUDWIG, T.A.V., BERTOLLI, L.M., FARIA, D.M. \& COSTIN, J.C. Gomphonema Ehrenberg e Gomphosphenia Lange-Bertalot (Bacillariophyceae) do Rio Maurício, Paraná, Brasil. Biota Neotrop., 9(4): http://www.biotaneotropica.org.br/v9n4/pt/abstract?inventory+bn00309042009.

Resumo: Pouco se conhece sobre a biogeografia e variabilidade morfológica das espécies de Gomphonema e Gomphosphenia no Brasil. Gomphonema é um gênero bem representado em riqueza e abundância na flora algal perifítica, principalmente pela secreção de mucilagem pelo campo de poros, o que facilita a adesão das células aos substratos. As amostras analisadas foram removidas das porções vegetativas de Potamogeton polygonus Chamess. \& Schltdl. e Egeria densa Planch., macrófitas coletadas no Rio Maurício, localizado no município de Fazenda Rio Grande, Paraná. A análise qualitativa do material resultou na determinação de 20 táxons. Onze espécies de Gomphonema e o gênero Gomphosphenia constituíram citações pioneiras para o Paraná. Os resultados de observações da ultra-estrutura de algumas espécies foi adicionado. A variabilidade do contorno valvar e os detalhes ultra-estruturais justificam futuras revisões taxonômicas de algumas espécies correlatas, como: G. gracile e Gomphonema sp.5, G. contraturris e G. salae, G. capitatum e G. laticollum.

Palavras-chave: diatomáceas, taxonomia, ultra-estrutura, ambiente lótico. 


\section{Introdução}

Representantes do gênero Gomphonema Ehrenberg são comuns nas comunidades haptobentônicas dulcícolas. Caracterizam-se principalmente por apresentarem células cuneiformes em vista pleural e heteropolares em vista valvar, geralmente unidas a substratos sólidos por almofadas ou pedúnculos de mucilagem, liberados através de campo de poros localizado na porção extrema basal da valva. O plastídio é único, em forma de "H", com pirenóide central, mas lateralmente deslocado (Cox 1996, Round et al. 1990). Aproximadamente 90 espécies de Gomphonema são relatadas para a América do Sul, entre as quais 28 foram recentemente propostas (Reichardt 1995, Lange-Bertalot et al. 1996, Metzeltin \& Lange-Bertalot 1998, 2007, Rumrich et al. 2000, Metzeltin et al. 2005).

O gênero apresenta várias espécies cosmopolitas, geralmente bem representadas quanto à riqueza e abundância nos ambientes aquáticos, mas sua taxonomia interespecífica é dificultada pela ampla variação morfológica das frústulas (Krammer \& Lange-Bertalot, 1986, 1991). Poucos estudos foram publicados com o objetivo de esclarecer a problemática taxonômica específica do gênero Gomphonema, podendo-se destacar Reichardt \& Lange-Bertalot (1991), Kociolek \& Stoermer (1991), Reichardt (1997, 1999, 2001, 2007, 2008), Kociolek \& Kingston (1999). Outras contribuições existentes, em sua maior parte, resultaram de trabalhos florísticos estrangeiros ou de materiais de regiões tropicais sul americanas examinados por pesquisadores estrangeiros (Metzeltin \& Lange-Bertalot 1998, 2007, Metzeltin et al. 2005).

O gênero Gomphosphenia, por sua vez, foi proposto por Lange-Bertalot (1995) com base em indivíduos com frústulas retangulares a cuneiformes em vista pleural, valvas pouco ou fortemente heteropolares e ausência de campo apical de poros. As aréolas, alongadas transapicalmente, diferem das encontradas em Gomphonema que são apicalmente alongadas, em forma de vírgula ou de meia lua. Ocorrem em ambientes dulcícolas incluindo cerca de dez espécies, entre as quais cinco registradas para a América do Sul: G. lingulatiformis Lange-Bertalot \& Reichardt, G. oahuensis (Hustedt) Lange-Bertalot, G. paradoxa Lange-Bertalot, G. tackei (Hustedt) Lange-Bertalot, G. tenerrima (Hustedt) Reichardt (Rumrich et al. 2000, Metzeltin \& Lange-Bertalot 1998, 2007). São escassos os trabalhos que apresentam espécies de Gomphosphenia, podendo-se destacar Lange-Bertalot (1995) e Reichardt (1999).

No Brasil, estudos exclusivos sobre os gêneros Gomphonema e Gomphosphenia são inexistentes. As espécies encontradas são registradas em inventários florísticos, geralmente sem um estudo mais aprofundado da morfologia e ultra-estrutura das frústulas e suas implicações taxonômicas. Cerca de 22 espécies de Gomphonema já foram registradas para os ambientes aquáticos paranaenses. Entre os trabalhos sobre a diatomoflórula perifítica em ambientes lóticos que incluem o gênero Gomphonema, podem-se destacar os estudos realizados no segmento do manancial do Rio Passaúna (Lozovei \& Shirata 1990), na confluência dos rios Iraí, Atuba e Pequeno (Contin 1990), na região do arroio Sampaio (Rodrigues \& Lobo 2000, Oliveira et al. 2001, 2002) e no Rio Jaú (Díaz-Castro et al. 2003). Destacam-se também trabalhos com enfoque em qualidade da água, como Lobo et al. (2004a) no Rio Pardinho, Lobo et al. (2004b) nos arroios Sampaio, Grande e Bonito, Lobo et al. (2004c) nos córregos Condor e Capivara, Salomoni et al. (2006) no Rio Gravataí e Schneck et al. (2008) no Rio das Antas. Todos estes estudos foram realizados na região sul do país e o mais representativo em número de espécies de Gomphonema foi o de Contin (1990) que registrou 14 espécies.

Este trabalho teve por objetivo principal realizar o estudo taxonômico das espécies de Gomphonema e Gomphosphenia aderidas a macrófitas aquáticas submersas nas cavas do Rio Maurício, município de Fazenda Rio Grande, Paraná, Brasil, adicionando-se informações sobre a estrutura de alguns táxons.

\section{Material e Métodos}

O Rio Maurício é um dos tributários da margem esquerda do Rio Iguaçu. Faz divisa entre os municípios de Araucária e Fazenda Rio Grande, drenando os municípios de Fazenda Rio Grande e Mandirituba, na região metropolitana de Curitiba, Paraná. A cabeceira do Rio Maurício é considerada moderadamente conservada e está localizada próxima a BR-116. A sub-bacia do Rio Maurício tem fundamental importância por constituir um manancial para o abastecimento público, com uma área de drenagem de $138 \mathrm{~km}^{2}$ (Prefeitura do Município de Araucária 2006, Andreoli et al. 1999).

As amostras foram coletadas em uma propriedade particular (Pesque-pague Sr. Amauri Antônio Baudan), com área total

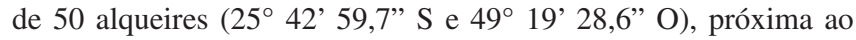
km 129 da BR-116.

A extração indiscriminada de areia e argila na região proporcionou a formação de cavas que são alimentadas por um canal ligado ao Rio Maurício. Segundo o IAP (2005), apesar de enquadrado como Classe 2 de acordo com a Resolução CONAMA 20/86, o Rio Maurício apresentou condição de qualidade compatível com a Classe 3 (CONAMA, 1986), ou seja, água medianamente poluída.

Exemplares das macrófitas aquáticas Potamogeton polygonus Chamess. \& Schltdl. (Potamogetonaceae) e Egeria densa Planch. (Hydrocharitaceae) foram coletados em maio de 2006, em um canal raso (50 $\mathrm{cm}$ de profundidade), derivado do Rio Maurício e que abastece as cavas. Este canal não apresenta sombreamento, tem fundo arenoso com sedimentos e pedregulhos finos, e possui aproximadamente $5 \mathrm{~m}$ de comprimento, distando cerca de $700 \mathrm{~m}$ da BR 116 e da área de extração de areia. Partes dos ramos submersos das macrófitas foram raspadas com escova de cerdas macias para extração de amostras perifíticas. O material resultante foi oxidado segundo a técnica de Simonsen (1974) modificada por Moreira-Filho \& Valente-Moreira (1981) e lâminas foram confeccionadas com resina Naphrax (I.R. = 1,74). As diatomáceas foram determinadas em microscópio óptico (MO) Olympus BX-40 e as imagens obtidas através de câmera Olympus DP-071. Adicionalmente, prepararam-se suportes de alumínio com amostra oxidada, que depois de metalizados com ouro em aparelho Balzers SCD030, foram observados em microscópio eletrônico de varredura (MEV) Jeol 6360LV para visualização da ultra-estrutura das frústulas de algumas espécies.

As principais obras utilizadas para as determinações taxonômicas foram citadas após a descrição de cada táxon. A terminologia empregada baseou-se em Barber \& Haworth (1981), Hendey (1964) e Round et al. (1990). As amostras foram tombadas no Herbário da Universidade Federal do Paraná (UPCB).

\section{Resultados e Discussão}

Um total de 20 táxons foi determinado, sendo destes 15 em nível específico ou infra-específico e cinco não apresentaram identidade reconhecida na literatura pesquisada. Dos táxons encontrados apenas um foi enquadrado no gênero Gomphosphenia.

\section{Descrição dos táxons encontrados}

1. Gomphonema angustatum (Kützing) Rabenhorst, Fl. Eur. Alg. I, p. $283,1864$.

Basiônimo: Sphenella angustata Kützing, Kies. Bacill. Diat., p. 83, pl.8, Figura 4, 1844. 
Valvas estreitamente clavado-lanceoladas, ápices sub-rostrados a atenuados e bases atenuadas. Área axial linear e estreita. Área central unilateral formada pelo encurtamento de uma estria mediana, estigma presente. Rafe reta ou ligeiramente sinuosa, com extremidades proximais sutilmente fletidas para o lado do estigma. Estrias paralelas, levemente radiadas nas extremidades e mais espaçadas na região mediana da valva, aréolas inconspícuas. Compr.: 14,2-33,2 $\mu \mathrm{m}$; larg.: 4,7-5,5 $\mu \mathrm{m}$; 13-20 estrias em $10 \mu \mathrm{m}$.

Material examinado: BRASIL. Paraná: Fazenda Rio Grande, Rio Maurício, perifíton em Egeria densa, VIII-IV-2006, Costin s.n.(UPCB58051); perifíton em Potamogeton polygonus, VIII-IV-2006, Costin s.n. (UPCB58052);

Obras consultadas: Rumrich et al. (2000), Metzeltin et al. (2005);

Citações para o Estado: Contin (1990), Cetto et al. (2004).

2. Gomphonema capitatum Ehrenberg, Infus., 217, pl. 18: Figura 2, 1838 ;

Valvas clavadas com região mediana intumescida. Ápices amplamente arredondados e bases arredondadas. Área axial linear. Área central circular a elíptica, delimitada pelo encurtamento irregular das estrias medianas, estigma presente. Rafe fracamente sinuosa, extremidades proximais dilatadas em poro e fletidas em direção ao estigma e fissuras terminais em forma de gancho, fletidas opostamente ao estigma. Estrias unisseriadas e radiadas, irregularmente encurtadas na região mediana, aréolas conspícuas. Compr.: 32-57 $\mu \mathrm{m}$; larg.: 8-12 $\mu \mathrm{m}$; 10-12 estrias em $10 \mu \mathrm{m} ; 20$ aréolas em $10 \mu \mathrm{m}$.

Em MEV, os espécimes apresentaram depressões arredondadas em toda extensão da área axial da rafe, estigma externamente arredondado e internamente em forma de fenda transversal sobre um nódulo central proeminente, rafe sinuosa com extremidades proximais retas, levemente dilatadas e fletidas do lado interno, extremidades distais da rafe fletidas para o lado oposto ao estigma terminando em proeminente helictoglossa, pseudosepto ausente, campo de poros delicados, estrias unisseriadas compostas por aréolas em forma de "C", interestrias robustas.

Comentário: em todos os exemplares observados em MEV foram constatadas depressões arredondadas na área axial da valva. Apesar desta característica não ter sido registrada por Reichardt (2001), optou-se por enquadrar os exemplares em G. capitatum devido as demais particularidades da valva serem semelhantes às descritas para espécie.

G. capitatum se assemelha à G. laticollum e G. truncatum Ehrenberg com relação à variação métrica e características morfológicas da valva, contudo estas espécies se diferenciam pelo fato de $G$. laticollum apresentar constrição menos pronunciada próxima às extremidades da valva e G. truncatum possuir estrias parcialmente ou totalmente compostas por fileira dupla de aréolas (Reichardt 2001).

Há registros de G. truncatum para o Estado do Paraná, contudo alguns destes correspondem à G. laticollum, sendo que apenas o registro realizado por Lozovei \& Shirata (1990) não pôde ser confirmado uma vez que a distinção entre $G$. capitatum e G. truncatum só pode ser feita em MEV e no trabalho citado não há descrição e/ou ilustração da ultra-estrutura da valva.

Material examinado: BRASIL. Paraná: Fazenda Rio Grande, Rio Maurício, perifíton em Egeria densa, VIII-IV-2006, Costin s.n. (UPCB58051); perifíton em Potamogeton polygonus, VIII-IV-2006, Costin s.n. (UPCB58052).

Obra consultada: Reichardt (2001).

Citação para o Estado: primeiro registro para o Paraná.
3. Gomphonema contraturris Lange-Bertalot \& Reichardt, Biblioth. Diatomol. 27:57, pl. 78: Figuras 2-9, pl. 79: Figuras 1-5, 1993.

Valvas clavadas, com intumescimento na região mediana e leve constrição entre a região mediana e o ápice. Ápices cuneados a sub-rostrados e bases arredondadas. Área axial linear. Área central retangular, delimitada pelo encurtamento de uma estria em cada lado da estria mediana. Estigma presente. Rafe sinuosa com extremidades proximais da rafe dilatadas em poro fletidas para o lado em que o estigma está presente. Estrias levemente radiadas, mais espaçadas na região mediana, aréolas conspícuas em MO. Compr.: 65-67,3 $\mu \mathrm{m}$; larg.: 13,6-16 $\mu \mathrm{m}$; 8-10 estrias em $10 \mu \mathrm{m} ; 20-24$ aréolas em $10 \mu \mathrm{m}$.

Comentário: esta espécie se distingue de G. turris principalmente pela forma das aréolas observadas em MEV (pouco curvadas a quase lineares em $G$. contrarris e em forma de "C" em G. turris) (Lange-Bertalot 1993). Semelhança também pode ser notada entre $G$. contraturris e $G$. salae, mas esta última espécie apresenta maior densidade de estrias (12-14 em $10 \mu \mathrm{m})$, menor variação métrica (comprimento: $40-55 \mu \mathrm{m}$ e largura: $10-11 \mu \mathrm{m}$ ) e extremidades valvares cuneado-sub-rostradas (Metzeltin \& Lange-Bertalot 1998).

Material examinado: BRASIL. Paraná: Fazenda Rio Grande, Rio Maurício, perifíton em Potamogeton polygonus, VIII-IV2006, Costin s.n. (UPCB58052).

Obra consultada: Lange-Bertalot (1993).

Citação para o Estado: primeiro registro para o Paraná.

4. Gomphonema gracile Ehrenberg, Infus., 217, pl. 18, Figura 3, 1838.

Valvas lanceoladas a rombo-lanceoladas com ápices e bases atenuados. Área axial linear, estreita. Área central unilateral, formada pelo encurtamento de uma estria mediana. Estigma presente. Rafe reta a levemente sinuosa, extremidades proximais fletidas em direção ao estigma. Estrias paralelas a levemente radiadas, as medianas mais afastadas das adjacentes, areolação delicada. Compr.: 32,4-79,8 $\mu$ m; larg.: 7,9-13,4 $\mu \mathrm{m}$; 11-16 estrias em $10 \mu \mathrm{m}$.

Em MEV, as valvas apresentaram estigma internamente em forma de fenda transversal, rafe levemente sinuosa com extremidades proximais retas, dilatadas em poro e fletidas em forma de gancho, extremidades distais da rafe fletidas e terminando em proeminente helictoglossa, pseudosepto delicado tanto no ápice quanto na base, campo de poros delicado, estrias unisseriadas formadas por aréolas ocluídas por rota.

Comentário: Gomphonema gracile é um dos táxons que apresenta grande variabilidade morfológica em relação a contorno e dimensões valvares. Sugerem-se estudos populacionais e de material-tipo para melhor circunscrição da espécie.

Material examinado: BRASIL. Paraná: Fazenda Rio Grande, Rio Maurício, perifíton em Egeria densa, VIII-IV-2006, Costin s.n. (UPCB58051); perifíton em Potamogeton polygonus, VIII-IV-2006, Costin s.n. (UPCB58052).

Obras consultadas: Patrick \& Reimer (1975), Krammer \& Lange-Bertalot (1986).

Citações para o Estado: Moreira-Filho \& Momoli (1963), Moreira-Filho \& Momoli (1966), Moreira-Filho et al. (1973), Moreira-Filho et al. (1976), Cecy et al. (1976), Lozovei \& Luz (1976), Lozovei \& Hohmann (1977), Contin (1990), Moro \& Fürstenberger (1993), Moro et al. (1994), Fürstenberger \& Valente-Moreira (2000), Tavares \& Valente-Moreira (2000), Rodrigues \& Bicudo (2001), Bittencourt-Oliveira (2002), Cetto et al. (2004), Moura \& Bittencourt-Oliveira (2004), Ludwig et al. (2005). 
5. Gomphonema hawaiiense Reichardt, Nova Hedwigia, 81(1-2):119, pl. 2, Figuras 1-13, 2005.

Valvas clavado-lanceoladas a levemente rombo-lanceoladas com ápices arredondados a atenuado-arredondados e bases arredondadas. Área central indistinta, refringente. Área axial amplamente lanceolada, delimitada pelo encurtamento regular das estrias. Estigma presente. Rafe sinuosa com extremidades proximais dilatadas em pequenos poros, fletidas em direção ao estigma. Estrias unisseriadas levemente radiadas, nas extremidades, aréolas inconspícuas. Compr.: 32,6-55 $\mu \mathrm{m}$; larg.: 6,3-9,5 $\mu \mathrm{m}$; 16-20 estrias em $10 \mu \mathrm{m}$.

Em MEV, as valvas apresentaram internamente estigma em forma de fenda transversal situado em um nódulo central espessado, extremidades proximais da rafe fortemente fletidas em direção ao estigma, extremidades distais finalizando em proeminente helictoglossa, pseudosepto evidente.

Comentário: G. hawaiiense diferencia-se de G. clevei Fricke por este último apresentar extremidade valvar largamente arredondada.

Material examinado: BRASIL. Paraná: Fazenda Rio Grande, Rio Maurício, perifíton em Egeria densa, VIII-IV-2006, Costin s.n. (UPCB58051).

Obra consultada: Reichardt (2005).

Citação para o estado: citado como G. clevei var. clevei por Contin (1990).

6. Gomphonema lagenula Kützing, Bacill., p. 85, pl. 30, Figura 60, 1844.

Valvas lanceoladas a elíptico-lanceoladas com ápices subcapitados a sub-rostrados e bases sub-capitadas. Área axial linear e estreita. Área central retangular, delimitada pelo encurtamento de uma estria mediana. Estigma presente. Rafe reta, extremidades proximais fletidas para o lado em que o estigma está presente. Estrias unisseriadas, paralelas a levemente radiadas, as medianas mais afastadas das adjacentes, areolação inconspícua. Compr.: 16,6-26,1 $\mu \mathrm{m}$; larg.: 5,5-7,1 $\mu \mathrm{m}$; 13-20 estrias em $10 \mu \mathrm{m}$.

Em MEV, as valvas apresentaram estigma externamente arredondado e internamente em forma de uma fenda transversal, rafe reta com extremidades proximais externas dilatadas em poro e fletidas em direção ao estigma e internas em forma de gancho, extremidades distais da rafe fletidas e terminando em proeminente helictoglossa do lado interno, pseudosepto ausente, campo de poros delicado, estrias unisseriadas com aréolas ocluídas por rota.

Material examinado: BRASIL. Paraná: Fazenda Rio Grande, Rio Maurício, perifíton em Egeria densa, VIII-IV-2006, Costin s.n. (UPCB58051); perifíton em Potamogeton polygonus, VIII-IV-2006, Costin s.n. (UPCB58052).

Obra consultada: Metzeltin \& Lange-Bertalot (1998).

Citações para o Estado: citado como G. parvulum var. lagenula (Kützing) Frenguelli por Moreira-Filho \& Momoli (1963) e como G. parvulum por Contin (1990), Rodrigues (1991), Tavares \& Valente-Moreira (2000), Bittencourt-Oliveira (2002), Moura \& Bittencourt-Oliveira (2004), Ludwig et al. (2005).

7. Gomphonema laticollum Reichardt in Jahn et al., Studies on Diatoms, p. 199, pl. 5, Figuras. 1-14, 2001.

Valvas clavadas, com intumescimento na região mediana e constrição pouco acentuada entre a região mediana e o ápice. Ápices amplamente arredondados e bases atenuado-arredondadas. Área axial linear. Área central irregular delimitada pelo encurtamento irregular das estrias medianas. Estigma presente. Rafe sinuosa com extremidades proximais dilatadas em poro, fletidas para o lado do estigma. Estrias unisseriadas e radiadas formadas por aréolas conspícuas. Compr.: 35,5-51 $\mu \mathrm{m}$; larg.: 9,5-13,4 $\mu \mathrm{m}$; 10-14 estrias em $10 \mu \mathrm{m} ; 18-20$ aréolas em $10 \mu \mathrm{m}$.

A observação da ultra-estrutura externa da valva revelou abertura do estigma arredondada, rafe sinuosa com extremidades proximais levemente dilatadas em poro, campo de poros delicado e estrias unisseriadas.

Material examinado: BRASIL. Paraná: Fazenda Rio Grande, Rio Maurício, perifíton em Egeria densa, VIII-IV-2006, Costin s.n. (UPCB58051).

Obras consultadas: Reichardt (2001), Metzeltin et al. (2005). Citação para o Estado: citado como G. truncatum Ehrenberg por Rodrigues (1991), Moro \& Fürstenberger (1993), Ludwig et al. (2005), e como G. truncatum var. capitatum (Ehrenberg) Patrick por: Lozovei \& Shirata (1990), Moro et al. (1994).

8. Gomphonema parallelistriatum Lange-Bertalot \& Reichardt, Biblioth. Diatomol. 27:68, pl. 76: Figuras 11-16, 1993.

Valvas clavadas, tendendo a elíptico-clavadas em indivíduos menores, com ápices arredondados e bases atenuadas. Área axial linear. Área central unilateral delimitada pelo encurtamento de uma estria mediana. Estigma presente. Rafe reta a levemente sinuosa com extremidades proximais dilatadas em poros e fletidas para o lado do estigma. Estrias unisseriadas, paralelas, levemente mais espaçadas na região mediana, com aréolas incon-

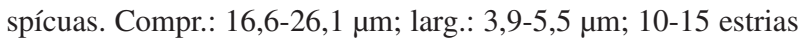
em $10 \mu \mathrm{m}$.

Comentário: os exemplares analisados foram incluídos nesta espécie pelas estrias paralelas e sua disposição na área central e forma do ápice. Entretanto, a população analisada apresentou a forma da base da valva mais aguda do que a registrada na literatura.

Material examinado: BRASIL. Paraná: Fazenda Rio Grande, Rio Maurício, perifíton em Potamogeton polygonus, VIII-IV2006, Costin s.n. (UPCB58052).

Obras consultadas: Krammer \& Lange-Bertalot (1991) e Lange-Bertalot (1993).

Citação para o Estado: primeiro registro para o Paraná.

9. Gomphonema parvulum (Kützing) Kützing, Spec. Alg., p. 65, 1849.

Basiônimo: Sphenella parvula Kützing, Kies. Bacill. Diat., p. 83, pl. 30, Figura 63, 1844.

Valvas lanceoladas a elíptico-lanceoladas nas formas menores, com ápices sub-rostrados e bases atenuado-arredondadas. Área axial linear, estreita. Área central irregular e estreita, delimitada pelo encurtamento irregular de uma estria mediana. Estigma presente. Rafe reta a levemente sinuosa, extremidades proximais fletidas para o lado do estigma, fissuras terminais poroidais. Estrias unisseriadas, paralelas a levemente radiadas nas extremidades, aréolas inconspícuas. Compr.: 16,6-27,6 $\mu \mathrm{m}$; larg.: 4,7-6,3 $\mu \mathrm{m}$; 12-18 estrias em $10 \mu \mathrm{m}$.

Internamente, em MEV, a espécie apresenta estigma em forma de fenda transversal, rafe com extremidades proximais fletidas em direção ao estigma e em forma de gancho, extremidades distais terminando em proeminente helictoglossa, pseudosepto ausente, campo de poros delicado.

Material examinado: BRASIL. Paraná: Fazenda Rio Grande, Rio Maurício, perifíton em Egeria densa, VIII-IV-2006, Costin s.n. (UPCB58051); perifíton em Potamogeton polygonus, VIII-IV-2006, Costin s.n. (UPCB58052).

Obras consultadas: Krammer \& Lange-Bertalot (1986, 1991). 
Citações para o Estado: Moreira-Filho \& Momoli (1966), Moreira-Filho et al. (1973), Moreira-Filho et al. (1976), Cecy et al. (1976), Lozovei \& Luz (1976), Lozovei \& Hohmann (1977), Moro \& Fürstenberger (1993), Moro et al. (1994), Rodrigues \& Bicudo (2001), Cetto et al. (2004).

10. Gomphonema pseudoaugur Lange-Bertalot, Arch. Hydrobiol. 56(2):213-214, Figuras 11-16, 79, 80, 1979.

Valvas lanceoladas, com ápices rostrados a sub-rostrados e bases atenuadas. Área axial linear. Área central unilateral delimitada pelo encurtamento de uma estria mediana. Estigma presente. Rafe reta a levemente sinuosa, com extremidades proximais dilatadas em poro e fletidas para o lado em que o estigma está presente. Estrias unisseriadas, paralelas a radiadas, mais espaçadas na região mediana, formadas por aréolas inconspícuas. Compr: 26,1- 41,1 $\mu \mathrm{m}$; larg.: 7,9-10,3 $\mu \mathrm{m} ; 10-16$ estrias em $10 \mu \mathrm{m}$.

Externamente, em MEV, as valvas possuem estigma elíptico, área axial ornamentada por pequenas depressões na valva, rafe sinuosa com extremidades proximais dilatadas e distais fletidas para o lado oposto ao estigma, campo de poros delicado, aréolas ocluídas por delicada rota.

Material examinado: BRASIL. Paraná: Fazenda Rio Grande, Rio Maurício, perifíton em Egeria densa, VIII-IV-2006, Costin s.n.(UPCB58051); perifíton em Potamogeton polygonus, VIII-IV-2006, Costin s.n. (UPCB58052).

Obra consultada: Krammer \& Lange-Bertalot (1986).

Citação para o Estado: Tavares \& Valente-Moreira (2000).

11. Gomphonema salae Lange-Bertalot \& Reichardt, Iconogr. Diatomol. 5: 548, Figuras 3-5, 1998.

Valvas clavadas, com intumescimento na região mediana e constrição pouco acentuada entre a região mediana e o ápice. Ápices cuneado-sub-rostrados e bases atenuado-arredondadas. Área axial levemente lanceolada. Área central unilateral, delimitada pelo encurtamento de uma estria mediana. Estigma presente. Rafe fracamente sinuosa, com extremidades proximais fletidas para o lado do estigma. Estrias unisseriadas, paralelas a levemente convergentes, mais espaçadas na região mediana, aréolas inconspícuas. Compr.: 41,2 $\mu \mathrm{m}$; larg.: $10 \mu \mathrm{m}$; 11 estrias em $10 \mu \mathrm{m}$.

Material examinado: BRASIL. Paraná: Fazenda Rio Grande, Rio Maurício, perifíton em Potamogeton polygonus, VIII-IV2006, Costin s.n. (UPCB58052).

Obra consultada: Metzeltin \& Lange-Bertalot (1998).

Citação para o Estado: primeiro registro para o Paraná.

12. Gomphonema sphaerophorum Ehrenberg, Ber. Akad. Wiss., p. $78,1845$.

Valvas amplamente clavado-lanceoladas, com ápices subrostrados a rostrado-capitados e bases capitadas a subcapitadas. Área axial linear a fracamente lanceolada. Área central unilateral formada pelo encurtamento de uma estria mediana. Estigma presente. Rafe levemente sinuosa, com extremidades proximais fletidas para o lado do estigma e dilatadas em poro. Estrias unisseriadas, paralelas a radiadas, às vezes não equidistantes entre si, mais espaçadas na região mediana, aréolas conspícuas. Compr.: 41,1-47 $\mu \mathrm{m}$; larg.: 13-15,8 $\mu \mathrm{m}$; 10-12 estrias em $10 \mu \mathrm{m}$; $18-20$ aréolas em $10 \mu \mathrm{m}$.

Material examinado: BRASIL. Paraná: Fazenda Rio Grande, Rio Maurício, perifíton em Potamogeton polygonus, VIII-IV2006, Costin s.n. (UPCB58052).

Comentário: G. sphaerophorum distingue-se de G. augur Ehrenberg por esta última apresentar ápices rostrados e bases atenuado-arredondadas (Metzeltin \& Lange-Bertalot 1998, Krammer \& Lange-Bertalot 1986, Patrick \& Reimer 1975).

Obras consultadas: Metzeltin \& Lange-Bertalot (1998) e Patrick \& Reimer (1975).

Citação para o Estado: primeiro registro para o Paraná.

13. Gomphonema turris Ehrenberg var turris, Phys. Abh. Akad. Wiss. Ber., p. 416, 1843.

Valvas clavado-lanceoladas, com região mediana intumescida e constrição pouco marcada entre a região mediana e o ápice. Ápices cuneado-sub-rostrados e bases atenuado-arredondadas. Área axial linear. Área central assimétrica, delimitada pelo encurtamento irregular das estrias medianas. Estigma presente. Rafe fracamente sinuosa com extremidades proximais fletidas para o lado em que o estigma está presente. Estrias unisseriadas, paralelas a radiadas e mais espaçadas na região mediana, aréolas

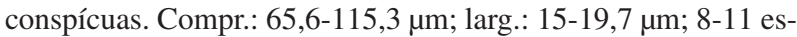
trias em $10 \mu \mathrm{m} ; 16-23$ aréolas em $10 \mu \mathrm{m}$.

Em MEV, a espécie apresenta estigma externamente elíptico e internamente em forma de fenda transversal, área axial ornamentada por pequenas depressões, rafe levemente sinuosa com extremidades proximais externas dilatadas e internas fletidas direção ao estigma e em forma de gancho, extremidades distais externas fletidas e internas finalizando em delicada helictoglossa, pseudosepto ausente, campo de poros delicado, estrias unisseriadas, aréolas ocluídas por complexa rota, interrompidas na junção entre superfície valvar e manto por uma linha longitudinal hialina.

Material examinado: BRASIL. Paraná: Fazenda Rio Grande, Rio Maurício, perifíton em Egeria densa, VIII-IV-2006, Costin s.n. (UPCB58051); perifíton em Potamogeton polygonus, VIII-IV-2006, Costin s.n. (UPCB58052).

Obra consultada: Patrick \& Reimer (1975).

Citações para o Estado: citado como G. augur var. turris (Ehrenberg) Lange-Bertalot por Rodrigues (1991), Ludwig et al. (2005).

14. Gomphonema turris var. coarctata (Frenguelli) Frenguelli, Rev. Mus. La Plata, Sec. Bot. 3:275, 1941.

Basiônimo: Gomphonema turris f. coarctata Frenguelli, An. Mus. Nac. Hist. Nat. 4:423, pl.4, Figuras 35-36, 1933.

Valvas clavadas a espatuladas com ápices sub-rostrados a levemente cuneado-sub-rostrados e bases atenuado-arredondadas. Área axial linear. Área central elíptica ou assimétrica, delimitada pelo encurtamento irregular das estrias medianas. Estigma presente. Rafe levemente sinuosa, com extremidades proximais dilatadas em poro e fletidas para o lado do estigma. Estrias unisseriadas, paralelas a radiadas, mais justapostas na base, aréolas

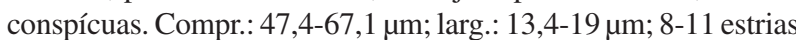
em $10 \mu \mathrm{m} ; 18-22$ aréolas em $10 \mu \mathrm{m}$.

Em MEV, o estigma é externamente elíptico e internamente em forma de fenda transversal, área axial ornamentada por depressões na valva, rafe levemente sinuosa com extremidades proximais externas dilatadas em poro e internas fletidas em direção ao estigma em forma de gancho, extremidades distais externas da rafe curvadas em direção oposta ao estigma e, internas, terminando em delicada helictoglossa, pseudosepto pouco proeminente, campo de poros delicado, estrias compostas por aréolas ocluídas por complexa rota, interrompidas na junção entre superfície valvar e manto por uma linha hialina longitudinal.

Comentário: difere da variedade típica pelo contorno valvar mais claviforme e ápices mais curtos e subapiculados. Frenguelli (1933) ao propor a f. coarctata, ilustrou um indivíduo com ápice sub-rostrado e com valva mais larga próximo ao ápice. Porém, 
quando realizou a transferência de forma para variedade (Frenguelli 1941), apresentou exemplares com ápices cuneado-sub-rostrados e com valvas mais largas na região mediana. $\mathrm{Na}$ amostra analisada do Rio Maurício foram encontrados os dois morfotipos. O morfotipo 1 apresentou valvas com formato mais espatulado, ápices menos destacados e área central elíptica, comprimento de 47,4-67,1 $\mu \mathrm{m}$, largura de 13,4-19 $\mu \mathrm{m}$, estrias e aréolas variaram de 8-11 e 18-22 em $10 \mu \mathrm{m}$, respectivamente (Figuras 67-70). O morfotipo 2 apresentou valvas clavadas, ápices destacados e área central linear, comprimento de 56,9-57,7 $\mu \mathrm{m}$, largura 13,4 $\mu \mathrm{m}$, estrias e aréolas variaram de 10-11 e 18-22 em $10 \mu \mathrm{m}$, respectivamente (Figuras 7172). Apesar de existirem algumas diferenças entre os morfotipos, optou-se por enquadrá-los no mesmo táxon em concordância com Frenguelli, porém sugerem-se estudos mais aprofundados da variação morfológica de ambas as formas para se averiguar a real identidade das mesmas.

Material examinado: BRASIL. Paraná: Fazenda Rio Grande, Rio Maurício, perifíton em Egeria densa, VIII-IV-2006, Costin s.n. (UPCB58051); perifíton em Potamogeton polygonus, VIII-IV-2006, Costin s.n. (UPCB58052).

Obras consultadas: Frenguelli $(1933,1941)$.

Citação para o Estado: primeiro registro para o Paraná.

\section{Gomphonema sp. 1}

Valvas lanceoladas, com ápices arredondados e bases atenuadoarredondadas. Área axial linear. Área central unilateral delimitada pelo encurtamento de uma estria mediana. Estigma presente. Rafe reta com extremidades proximais fletidas para o lado do estigma. Estrias unisseriadas, aréolas inconspícuas, paralelas a radiadas, as medianas mais espaçadas das demais. Compr.: $30-30,8 \mu \mathrm{m}$; larg.: 7,9-8,7 $\mu \mathrm{m}$; 16-19 estrias em $10 \mu \mathrm{m}$.

Comentário: os exemplares desta espécie apresentaram semelhança com G. gracile, porém as extremidades são menos agudas do que nesta última. Além disso, a proporção comprimento/largura mantém-se entre 3,5-4,2 em Gomphonema sp.1 e entre 5,2-5,6 em G. gracile.

Material examinado: BRASIL. Paraná: Fazenda Rio Grande, Rio Maurício, perifíton em Potamogeton polygonus, VIII-IV2006, Costin s.n. (UPCB58052).

Citação para o Estado: primeiro registro para o Paraná.

\section{Gomphonema sp.2}

Valvas lanceoladas, com ápices sub-rostrados e bases atenuadoarredondadas. Área axial linear. Área central unilateral delimitada pelo encurtamento irregular de uma estria mediana. Estigma presente. Rafe reta com extremidades proximais dilatadas em poro e fletidas para o lado do estigma. Estrias unisseriadas, radiadas, sendo apenas a mediana reta e mais afastada das demais. Aréolas inconspícuas. Compr.: 26,1-34 $\mu \mathrm{m}$; larg.: 4,7-7,9 $\mu \mathrm{m}$; 12-14 estrias em $10 \mu \mathrm{m}$.

Comentário: esta espécie é semelhante às formas de G. angustatum, entretanto difere pelas extremidades sub-rostradas e pela presença de estrias curvadas vizinhas à estria mediana reta.

Material examinado: BRASIL. Paraná: Fazenda Rio Grande, Rio Maurício, perifíton em Potamogeton polygonus, VIII-IV2006, Costin s.n. (UPCB58052).

Citação para o Estado: primeiro registro para o Paraná.

\section{Gomphonema sp.3}

Valvas lanceoladas com ápices cuneado-sub-rostrados e bases atenuado-arredondadas. Área axial linear. Área central unilateral delimitada pelo encurtamento de uma estria mediana. Estigma presente. Rafe reta com extremidades proximais dilatadas em poro e fletidas para o lado do estigma. Estrias unisseriadas, paralelas a radiadas em direção as extremidades, as medianas mais espaçadas, formadas por aréolas inconspícuas. Compr.: 59,2 $\mu \mathrm{m}$; larg.: 11,8 $\mu \mathrm{m} ; 11$ estrias em $10 \mu \mathrm{m} ; 20$ aréolas em $10 \mu \mathrm{m}$.

Comentário: o exemplar observado assemelha-se ao espécime ilustrado por Metzeltin \& Lange-Bertalot (2007, pl. 216, Figura 33.). Apesar dos autores citarem o táxon como uma espécie nova, estes não realizaram a proposição da mesma. Certa semelhança também foi constatada entre Gomphonema sp. 3 e formas menores de G. pseudoaugur e G. gracile, contudo diferem pela forma das extremidades, que nestas últimas são rostradas e atenuadas, respectivamente.

Material examinado: BRASIL. Paraná: Fazenda Rio Grande, Rio Maurício, perifíton em Potamogeton polygonus, VIII-IV2006, Costin s.n. (UPCB58052).

Citação para o Estado: primeiro registro para o Paraná.

\section{Gomphonema sp. 4}

Valvas lanceoladas com ápices estreitamente cuneados a atenuado-arredondados e bases atenuado-arredondadas. Área central indistinta. Área axial ampla, lanceolada a rômbicolanceolada, delimitada pelo encurtamento regular das estrias. Ausência de estigma. Rafe reta, com extremidades proximais dilatadas em pequenos poros, nódulo central refringente. Estrias unisseriadas, paralelas a levemente radiadas para o centro nas extremidades, regularmente encurtadas em toda a extensão da valva. Aréolas inconspícuas. Compr.: 17,4-37 $\mu \mathrm{m}$; larg.: 4-7 $\mu \mathrm{m}$; 12-18 estrias em $10 \mu \mathrm{m}$.

Em MEV, as valvas possuem área axial ornamentada por pequenas depressões, nódulo central espessado, rafe reta com extremidades proximais externas pouco dilatadas e internas fortemente fletidas para o mesmo lado e finalizando em gancho, extremidades distais externas fletidas em forma de foice e internas terminado em delicada helictoglossa, pseudosepto pouco pronunciado, campo de poros delicado, estrias compostas por aréolas lineares exceto próximo a área axial onde são em forma de "C".

Comentário: Gomphonema sp.4 apresentou semelhança com G. brasiliensoides Metzeltin, Lange-Bertalot \& GarcíaRodriguez, porém o padrão de estriação da valva foi a principal diferença constatada entre as espécies. Enquanto a primeira apresenta estrias bisseriadas com pequenas aréolas lineares (Metzeltin et al. 2005) a segunda possui estrias unisseridas com aréolas lineares em forma de " $\mathrm{C}$ " a alongadas. Estudos mais detalhados fazem-se necessários para se constatar se a espécie encontrada é nova para a ciência.

Material examinado: BRASIL. Paraná: Fazenda Rio Grande, Rio Maurício, perifíton em Egeria densa, VIII-IV-2006, Costin s.n. (UPCB58051); perifíton em Potamogeton polygonus, VIII-IV-2006, Costin s.n. (UPCB58052).

Citação para o Estado: primeiro registro para o Paraná.

\section{Gomphonema sp. 5}

Valvas lanceoladas a rombo-lanceoladas. Ápices atenuadoarredondados a sub-rostrados. Bases atenuado-arredondadas. Área axial linear, estreita. Área central unilateral, formada pelo encurtamento de uma estria mediana. Presença de estigma. Rafe sinuosa, extremidades proximais dilatadas em poros, fletidas para o lado do estigma. Estrias paralelas a radiadas, mais afastadas das adjacentes na região mediana. Areolação delicada. Compr.: 41,1-90,1 $\mu \mathrm{m}$; larg.: 7,9-14 $\mu \mathrm{m}$; 10-18 estrias em $10 \mu \mathrm{m}$; 20-24 aréolas em $10 \mu \mathrm{m}$.

Valvas com estigma externamente arredondado a levemente elíptico e internamente em forma de uma fenda transversal, área 

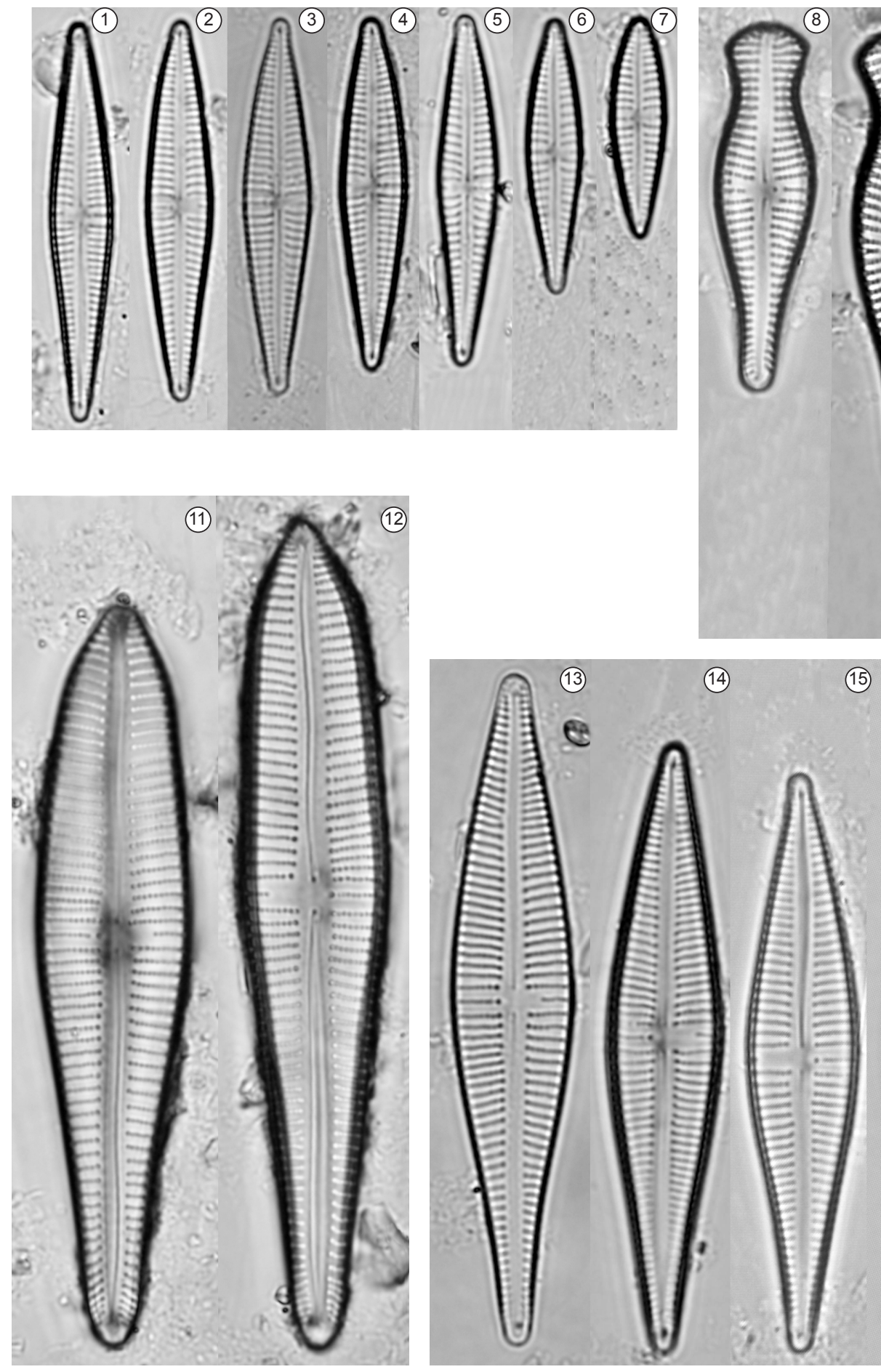

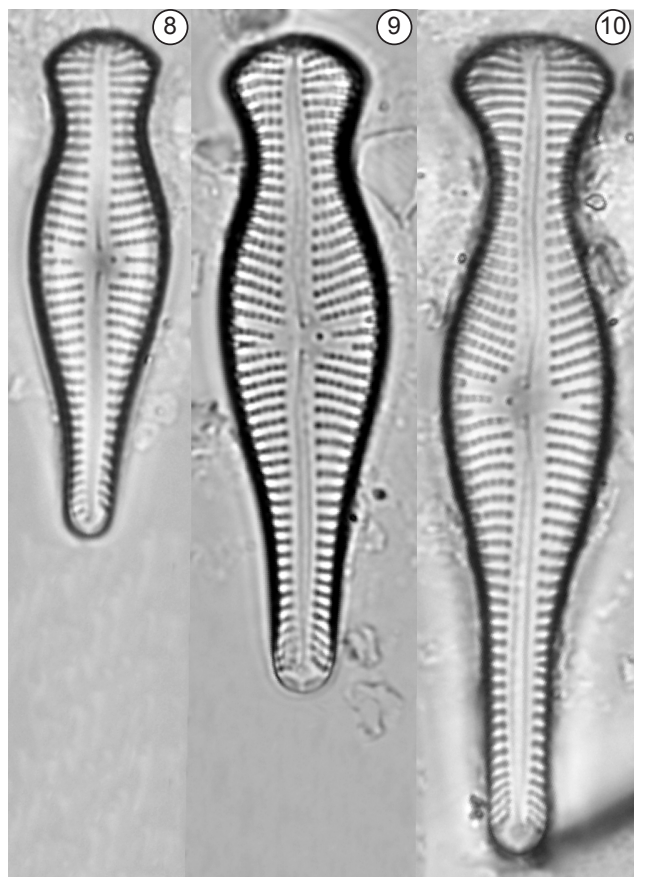

(15)

(16)

(17) $-$ (1.6)

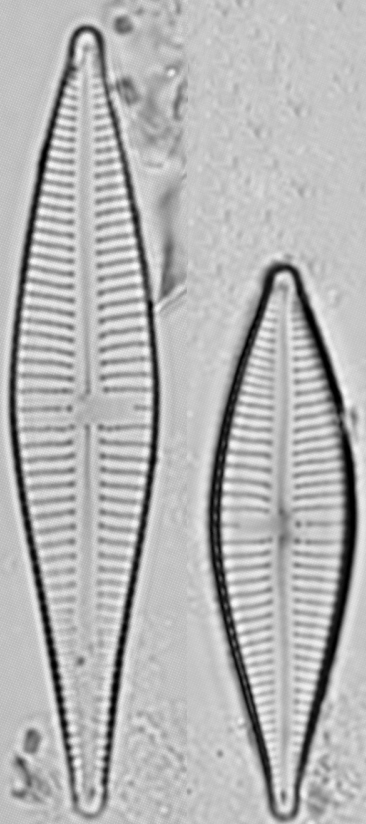

Figuras 1-17. Figuras. 1-7: Gomphonema angustatum. Figuras. 8-10: Gomphonema capitatum. Figuras. 11-12: Gomphonema contraturris. Figuras. 13-17: Gomphonema gracile. Escala: $10 \mu \mathrm{m}$.

Figures 1-17. Figures. 1-7: Gomphonema angustatum. Figures. 8-10: Gomphonema capitatum. Figures. 11-12: Gomphonema contraturris. Figures. 13-17: Gomphonema gracile. Scale: $10 \mu \mathrm{m}$. 
Tremarin P.I. et al.
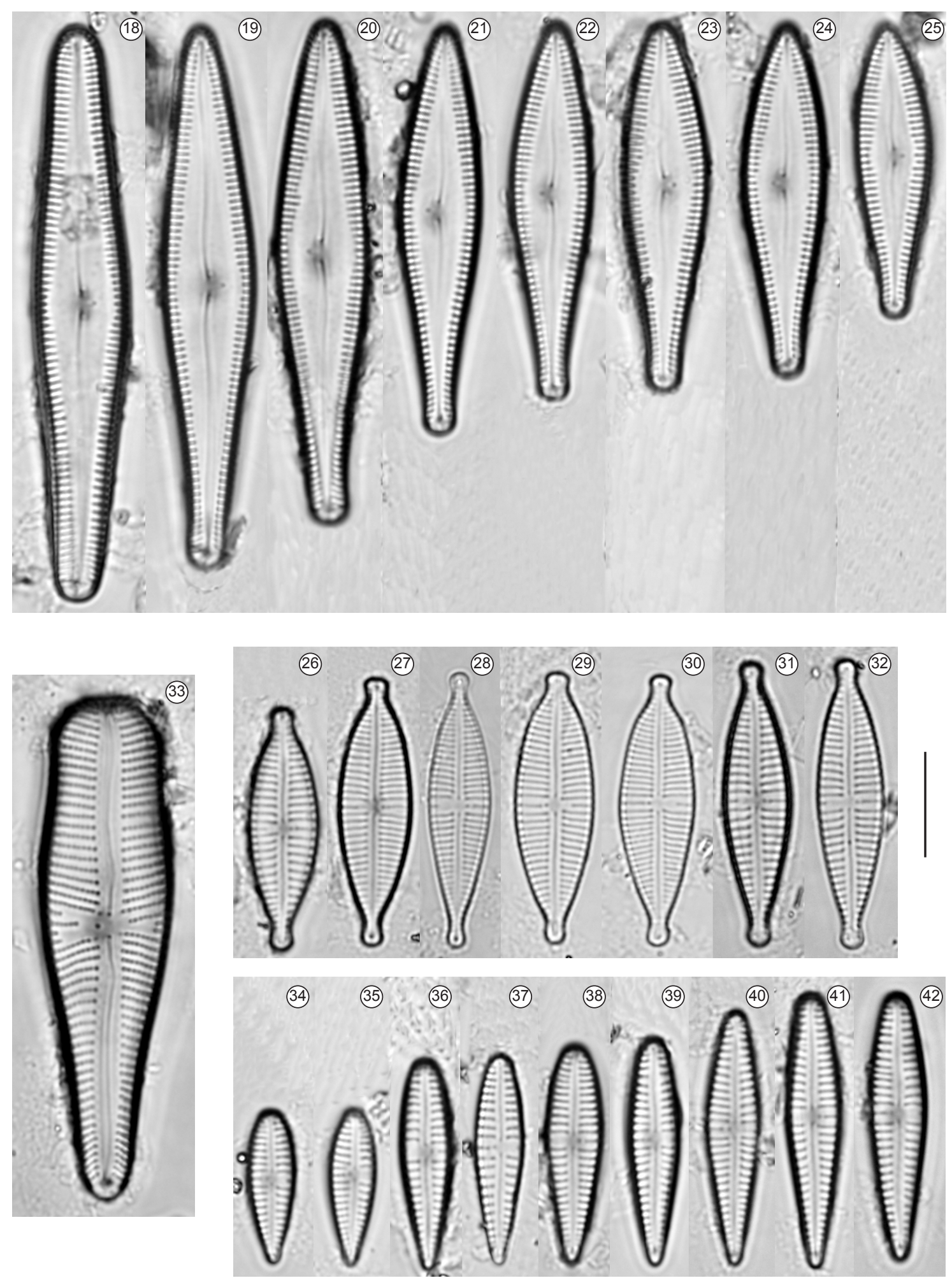

Figuras 18-42. Figuras. 18-25: Gomphonema hawaiiense. Figuras. 26-32: Gomphonema lagenula. Figura. 33: Gomphonema laticollum. Figuras. 34-42: Gomphonema parallelistriatum. Escala: $10 \mu \mathrm{m}$.

Figures 18-42. Figures. 18-25: Gomphonema hawaiiense. Figures. 26-32: Gomphonema lagenula. Figure. 33: Gomphonema laticollum. Figures. 34-42: Gomphonema parallelistriatum. Scale: $10 \mu \mathrm{m}$ 

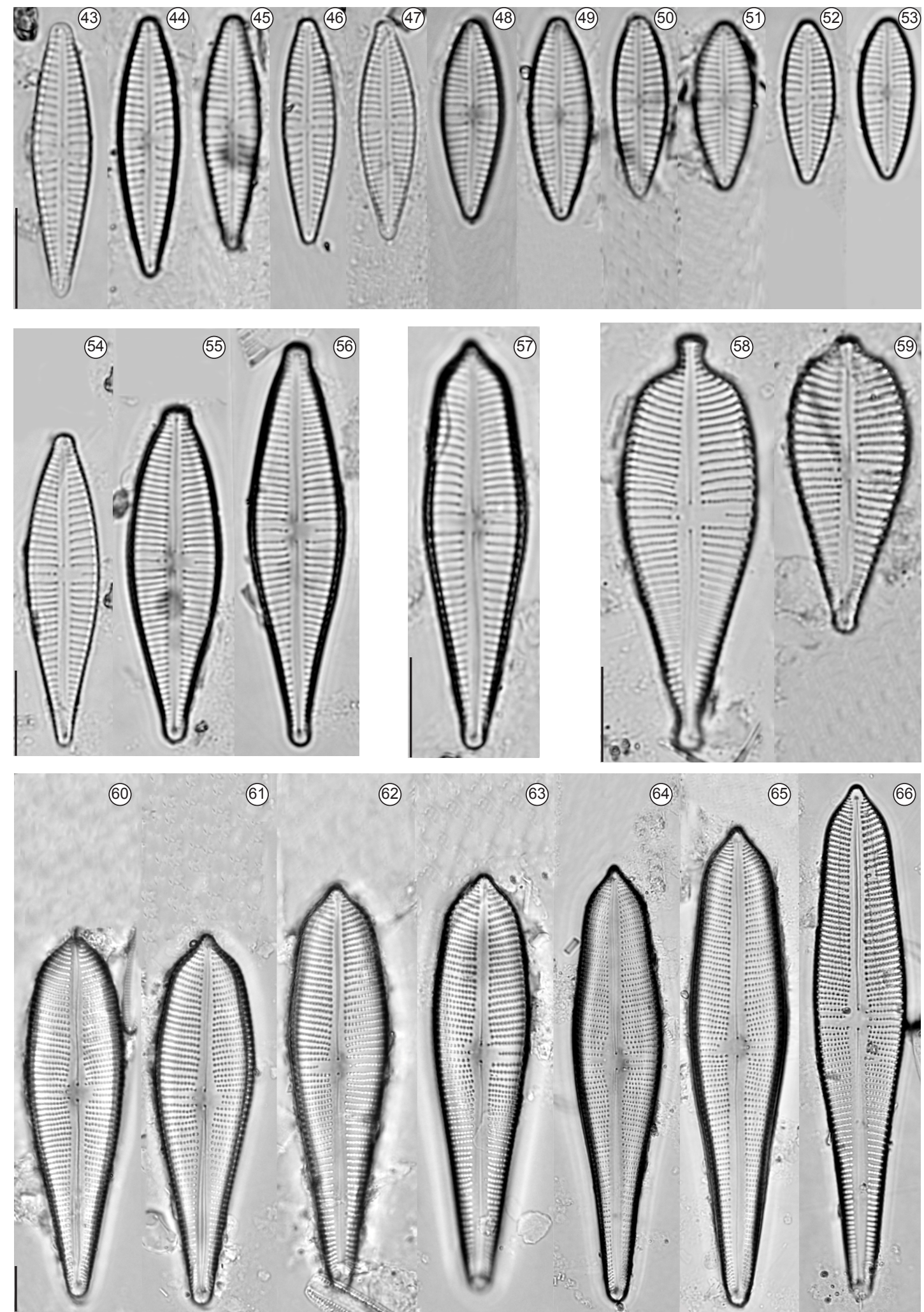

Figuras 43-66. Figuras. 43-53: Gomphonema parvulum. Figuras. 54-56: Gomphonema pseudoaugur. Figura. 57: Gomphonema salae. Figuras. 58-59: Gomphonema sphaerophorum. Figuras. 60-66: Gomphonema turris var. turris. Escala: $10 \mu \mathrm{m}$.

Figures 43-66. Figures. 43-53: Gomphonema parvulum. Figures. 54-56: Gomphonema pseudoaugur. Figure. 57: Gomphonema salae. Figures. 58-59: Gomphonema sphaerophorum. Figures. 60-66: Gomphonema turris var. turris. Scale: $10 \mu \mathrm{m}$. 

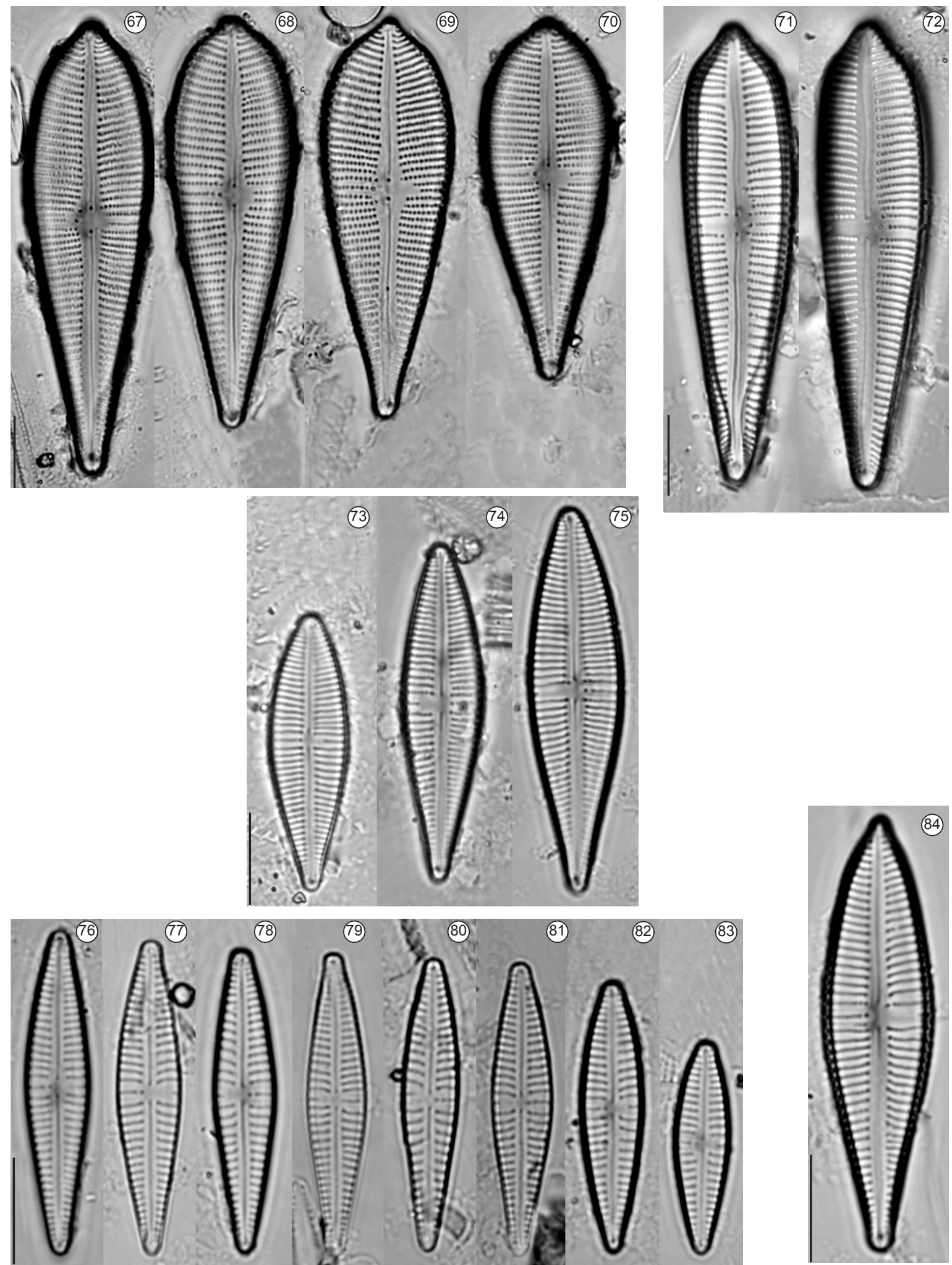

Figuras 67-84. Figuras. 67-72: Gomphonema turris var. coarctata. Figuras. 73-75: Gomphonema sp.1. Figuras. 76-83: Gomphonema sp.2. Figura. 84: Gomphonema sp.3. Escala: $10 \mu \mathrm{m}$.

Figures 67-84. Figures. 67-72: Gomphonema turris var. coarctata. Figures. 73-75: Gomphonema sp.1. Figures. 76-83: Gomphonema sp.2. Figure. 84: Gomphonema sp.3. Scale: $10 \mu \mathrm{m}$. 

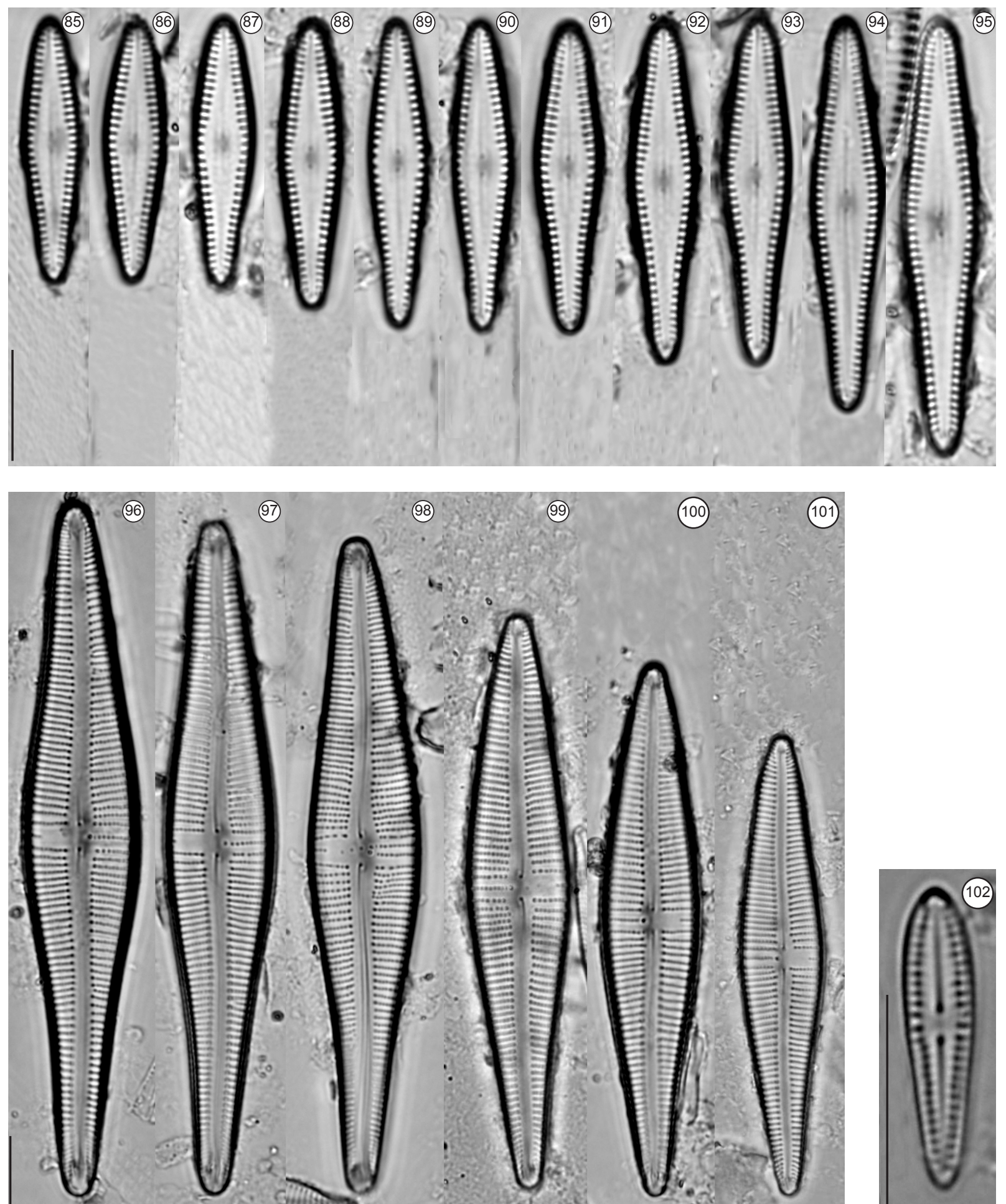

Figuras 85-102. Figuras. 85-95: Gomphonema sp.4. Figuras. 96-101: Gomphonema sp.5. Figura. 102: Gomphosphenia grovei var. lingulata. Escala: 10 $\mu$ m. Figures 85-102. Figures. 85-95: Gomphonema sp.4. Figures. 96-101: Gomphonema sp.5. Figure. 102: Gomphosphenia grovei var. lingulata. Scale: $10 \mu \mathrm{m}$. 

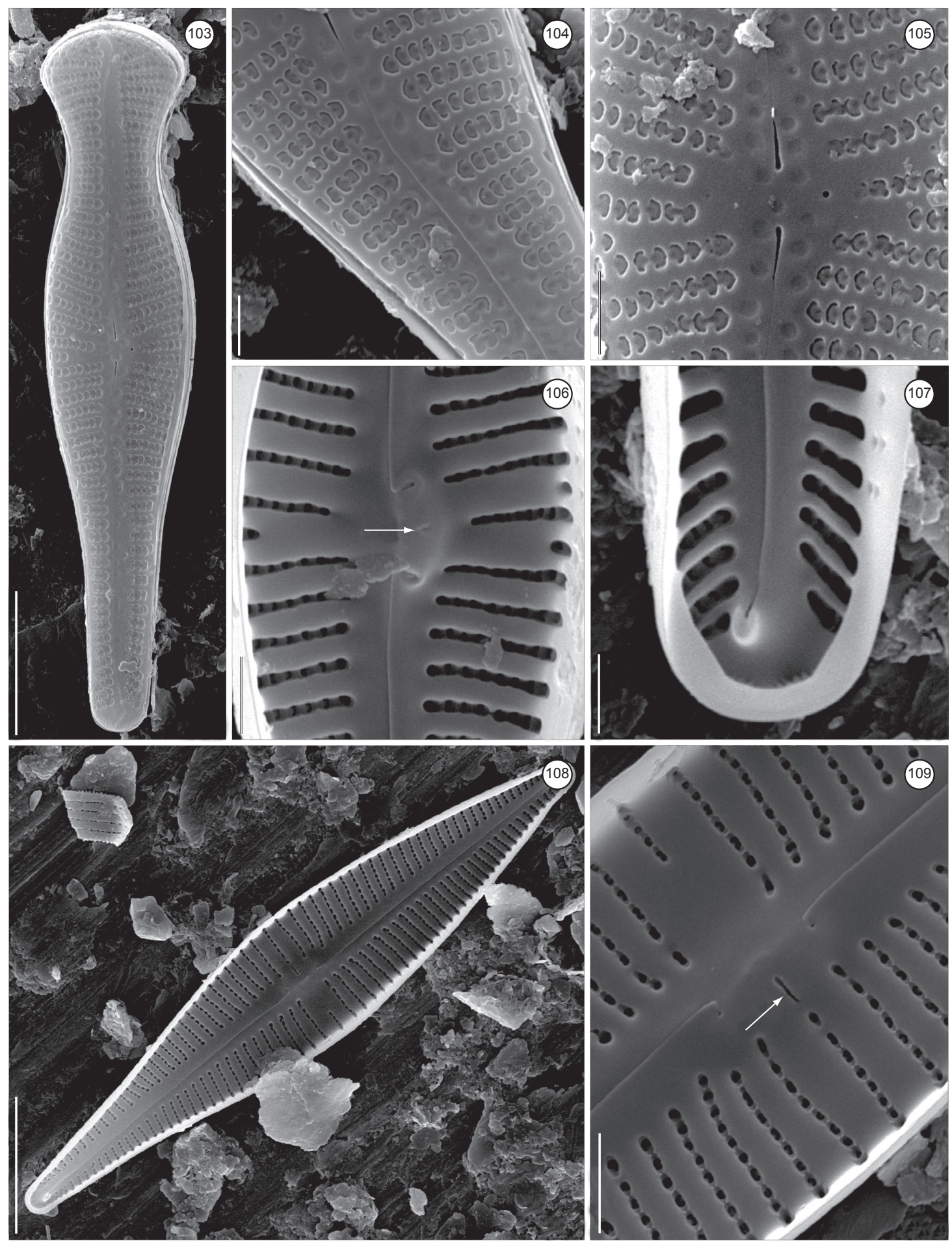

Figuras 103-109. Figuras 103-107 Gomphonema capitatum, MEV. Figura 103: vista geral externa da valva. Escala: 10 pm. Figura 104: detalhe da rafe e da ornamentação da área axial da rafe em vista externa. Escala: $2 \mu \mathrm{m}$. Figura 105: Estigma na área central da valva e estrias em forma de "C" em vista externa. Escala: $2 \mu \mathrm{m}$. Figura 106: vista interna das extremidades proximais da rafe e da abertura do estigma (seta). Escala: $2 \mu \mathrm{m}$. Figura 107: detalhe da helictoglossa. Escala: $2 \mu \mathrm{m}$. Figuras 108-109. Gomphonema gracile, MEV, vista interna. Figura 108: vista geral da valva. Escala: $10 \mu \mathrm{m}$. Figura 109: extremidades proximais da rafe e abertura do estigma (seta). Escala: $2 \mu \mathrm{m}$.

Figures 103-109. Figures 103-107 Gomphonema capitatum, SEM. Figure 103: external view of valve. Scale: $10 \mu$ m. Figure 104: detail of raphe and ornamentation of axial area. Scale: $2 \mu \mathrm{m}$. Figure 105: Note the stigma in the central area and "C"-like striae in external view. Scale: $2 \mu \mathrm{m}$. Figure 106: external view, proximal raphe ends and stigma opening (arrow). Scale: $2 \mu \mathrm{m}$. Figure 107: detail of helictoglossa. Scale: $2 \mu \mathrm{m}$. Figures 108-109. Gomphonema gracile, SEM, internal view. Figure 108: overview of valve. Scale: $10 \mu \mathrm{m}$. Figure 109: proximal raphe ends and stigma opening (arrow). Scale: $2 \mu \mathrm{m}$. 

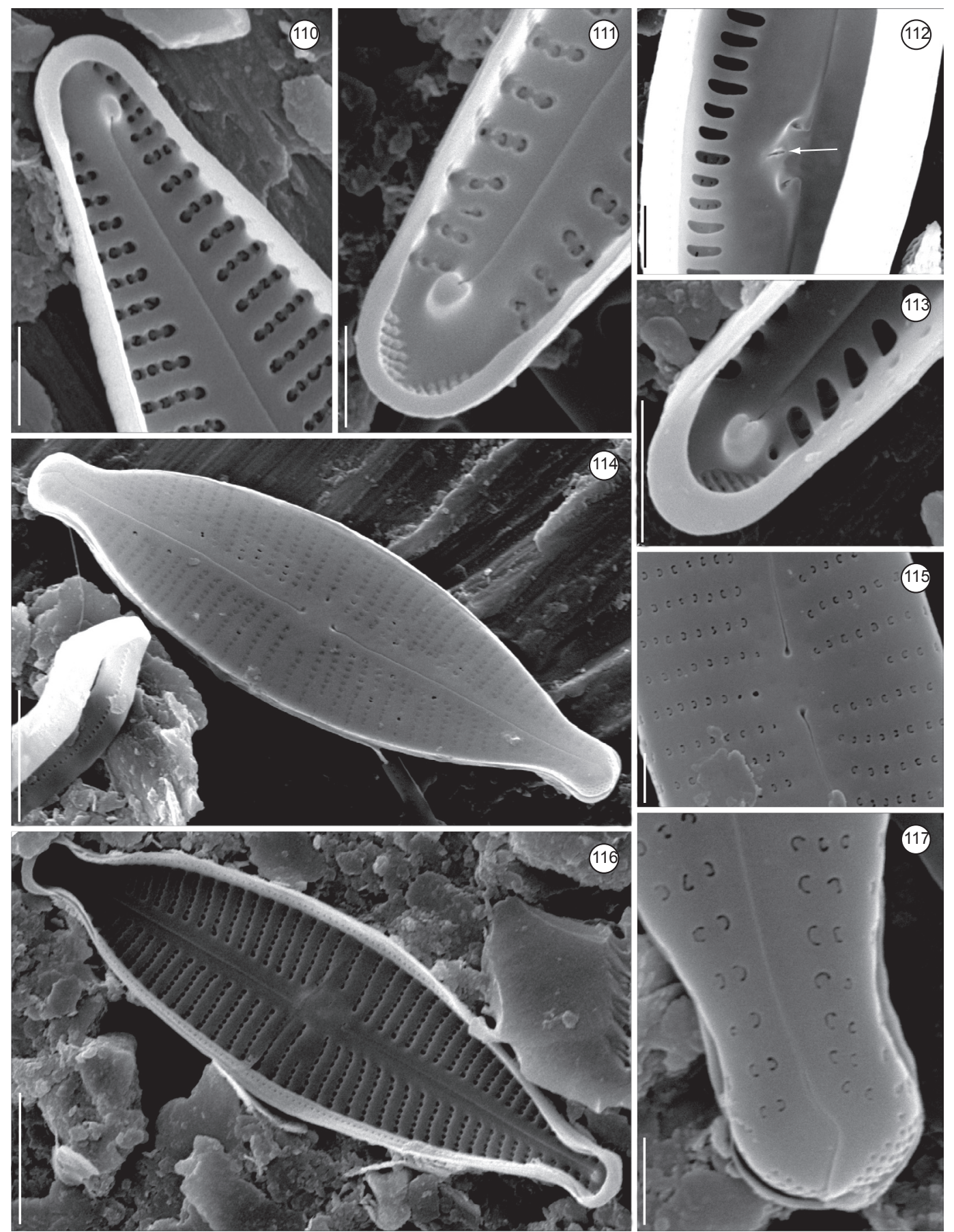

Figuras 110-117. Figuras 110-111. Gomphonema gracile, MEV, vista interna. Figura 110: pequena helictoglossa e pseudosepto pouco desenvolvido no ápice da valva. Escala: $2 \mu \mathrm{m}$. Figura 111: detalhe da helictoglossa e campo de poros na base da valva. Escala: $2 \mu \mathrm{m}$. Figuras 112-113. Gomphonema hawaiiense, MEV, vista interna. Figura 112: detalhe da área central da valva mostrando estrias encurtadas, nódulo central proeminente, extremidades proximais da rafe e abertura do estigma (seta). Escala: $2 \mu \mathrm{m}$. Figura 113: helictoglossa e pseudosepto desenvolvido na base da valva. Escala: $2 \mu \mathrm{m}$. Figuras 114-117. Gomphonema lagenula, MEV. Figura 114: vista geral externa da valva. Escala: $5 \mu \mathrm{m}$. Figura 115: área central mostrando abertura externa do estigma e extremidades proximais da rafe. Escala: $1 \mu \mathrm{m}$. Figura 116: vista geral interna da valva. Escala: $5 \mu \mathrm{m}$. Figura 117: vista externa das aréolas e campo de poros na base da valva. Escala: $1 \mu \mathrm{m}$.

Figures 110-117. Figures 110-111 Gomphonema gracile, SEM, internal view. Figure 110: small helictoglossa and pseudoseptum poorly develop in the apex of valve. Scale: $2 \mu \mathrm{m}$. Figure 111: detail of helictoglossa and basal pores field. Scale: $2 \mu \mathrm{m}$. Figures 112-113. Gomphonema hawaiiense, SEM, internal view. Figure 112: note the central area of valve with shortened striae, prominent central nodule, proximal raphe ends and stigma opening (arrow). Scale: $2 \mu \mathrm{m}$. Figure 113: helictoglossa and pseudoseptum develop in the valvar base. Scale: $2 \mu \mathrm{m}$. Figures 114-117. Gomphonema lagenula, SEM. Figure 114: external view of valve. Scale: $5 \mu \mathrm{m}$. Figure 115: central area showing the external opening of stigma and proximal raphe ends. Scale: $1 \mu \mathrm{m}$. Figure 116: internal view of valve. Scale: $5 \mu \mathrm{m}$. Figure 117: external view of areolae and basal pores field. Scale: $1 \mu \mathrm{m}$. 

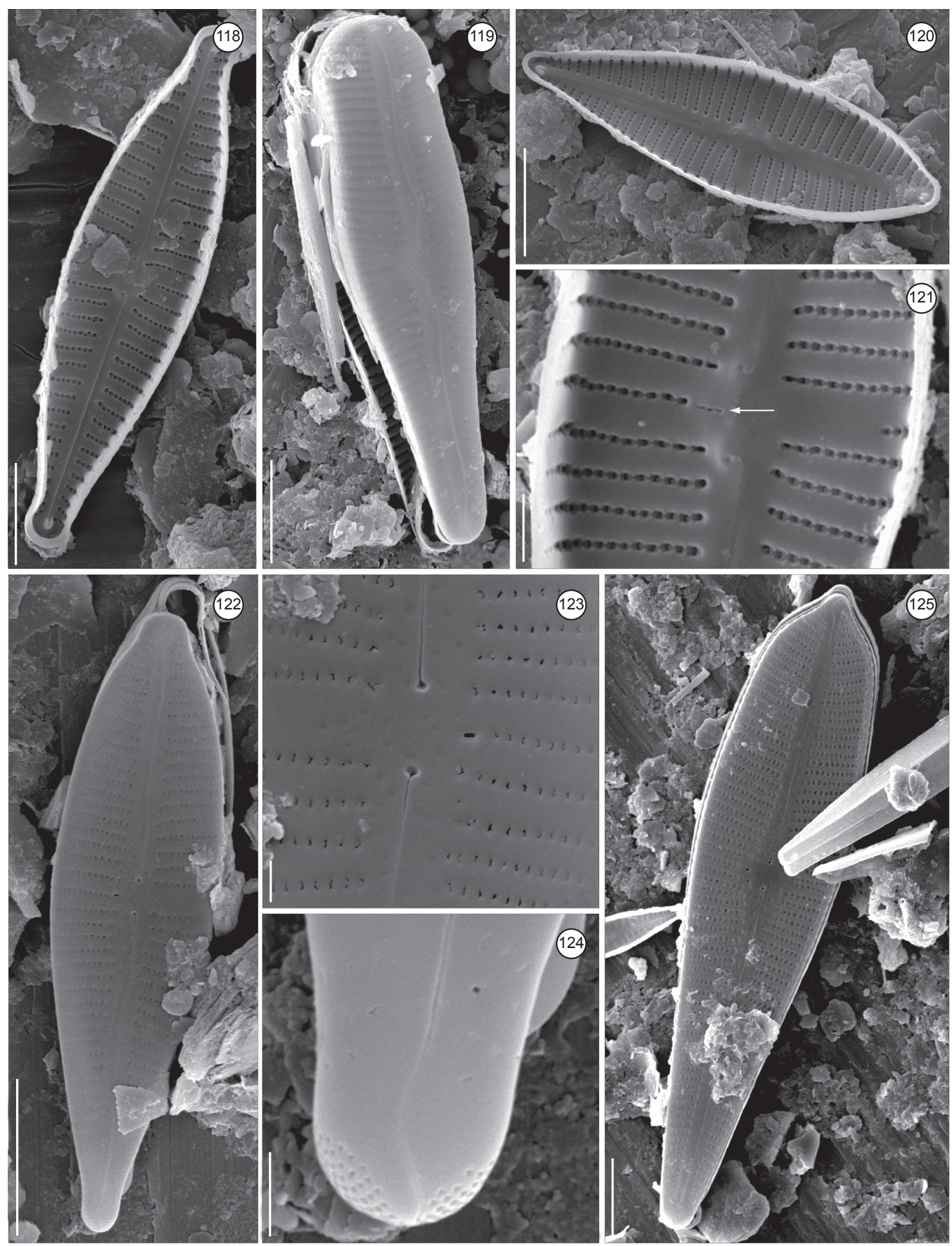

Figuras 118-124. Figura 118. Gomphonema lagenula, MEV, vista geral interna. Escala: $5 \mu$ m. Figura 119. Gomphonema laticollum, MEV, vista geral externa. Escala: $10 \mu \mathrm{m}$. Figuras 120-121. Gomphonema parvulum, MEV, vista interna. Figura 120: vista geral da valva. Escala 5 mm. Figura 121: detalhe das extremidades proximais da rafe e abertura do estigma (seta). Escala: $1 \mu \mathrm{m}$. Figuras 122-124. Gomphonema pseudoaugur, MEV. Figura 122: vista geral externa da valva. Escala: $10 \mu \mathrm{m}$. Figura 123: detalhe das extremidades proximais da rafe e abertura do estigma em vista externa. Escala: $1 \mu \mathrm{m}$. Figura 124: vista externa do campo de poros na base da valva. Escala: $1 \mu \mathrm{m}$. Figura 125. Gomphonema turris var. turris, MEV, vista geral externa da valva. Escala: $10 \mu \mathrm{m}$.

Figures 118-124. Figure 118. Gomphonema lagenula, SEM, internal view. Scale: $5 \mu \mathrm{m}$. Figure 119. Gomphonema laticollum, SEM, external view. Scale: $10 \mu \mathrm{m}$. Figures 120-121. Gomphonema parvulum, SEM, internal view. Figure 120: overview of valve. Scale $5 \mu \mathrm{m}$. Figure 121: detail of proximal raphe ends and stigma opening (arrow). Scale: $1 \mu \mathrm{m}$. Figures 122-124. Gomphonema pseudoaugur, SEM. Figure 122: external view of valve. Scale: $10 \mu \mathrm{m}$. Figure 123 : note the proximal raphe ends and stigma opening in external view. Scale: $1 \mu \mathrm{m}$. Figure 124: external view of basal pores filed. Scale: $1 \mu \mathrm{m}$. Figure 125 . Gomphonema turris var. turris, SEM, external view of valve. Scale: $10 \mu \mathrm{m}$. 

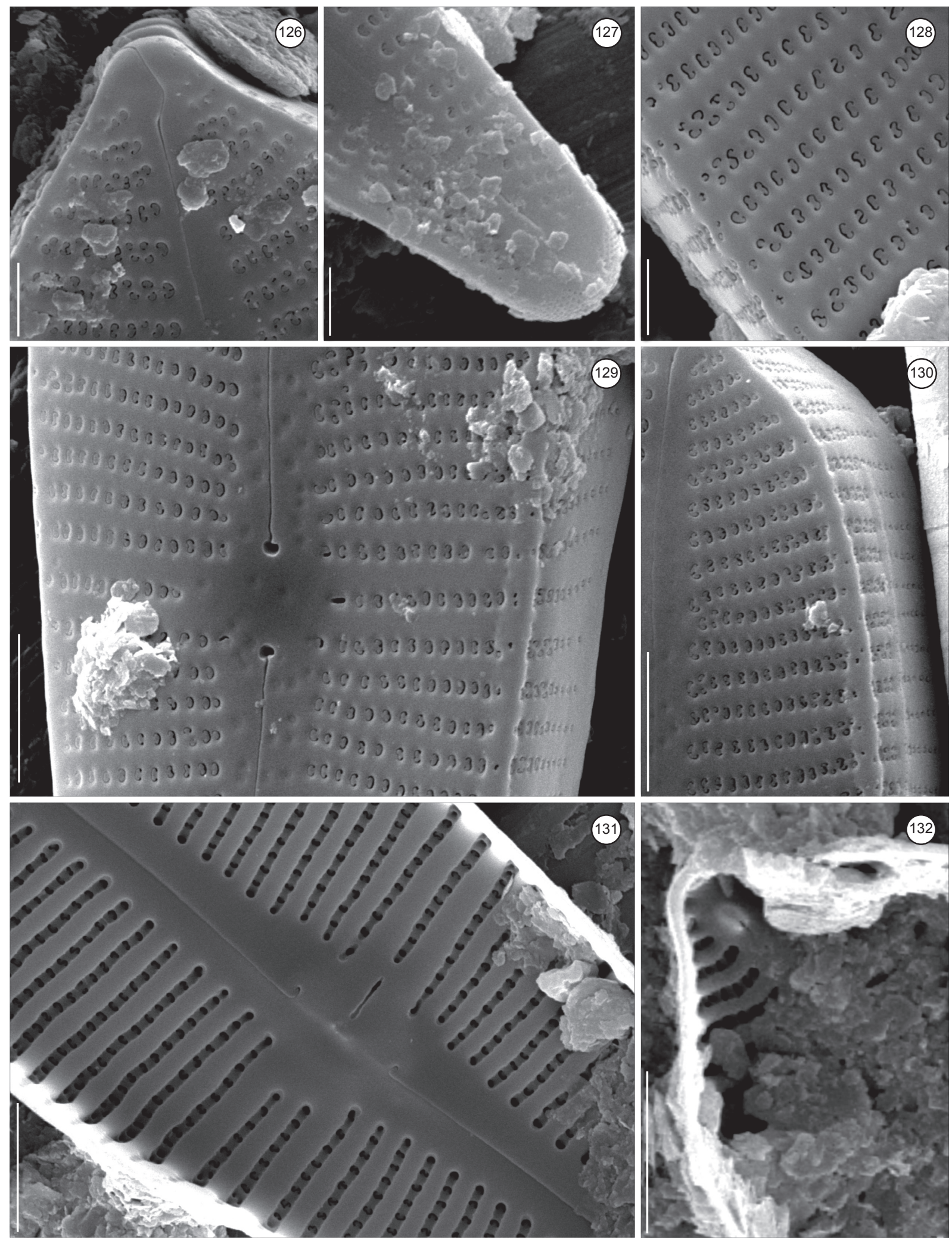

Figuras 126-132. Gomphonema turris var. turris, MEV. Figura 126: vista externa da extremidade distal da rafe no ápice da valva. Escala: $2 \mu$ m. Figura 127 : campo de poros na base da valva, vista externa. Escala: $2 \mu \mathrm{m}$. Figura 128: detalhe das aréolas. Escala: $2 \mu \mathrm{m}$. Figura 129: extremidades proximais da rafe e abertura externa do estigma. Escala: $5 \mu \mathrm{m}$. Figura 130: detalhe da linha hialina longitudinal na junção valva/manto. Escala: $5 \mu \mathrm{m}$. Figura: 131: vista interna da área central com extremidades proximais da rafe e abertura do estigma. Escala: $5 \mu \mathrm{m}$. Figura 132: pequena helictoglossa no ápice da valva. Escala: $5 \mu \mathrm{m}$.

Figures 126-132. Gomphonema turris var. turris, SEM. Figure 126: external view of distal raphe ends in the valvar apex. Scale: $2 \mu \mathrm{m}$. Figure 127: basal pores field, external view. Scale: $2 \mu \mathrm{m}$. Figure 128: detail of areolae. Scale: $2 \mu \mathrm{m}$. Figure 129: proximal raphe ends and external opening of stigma. Scale: $5 \mu \mathrm{m}$. Figure 130: note the hyaline longitudinal line in the valve/mantle junction. Scale: $5 \mu \mathrm{m}$. Figure: 131: internal view of central area with proximal raphe ends and stigma opening. Scale: $5 \mu \mathrm{m}$. Figure 132: small helictoglossa in the valvar apex. Scale: $5 \mu \mathrm{m}$. 

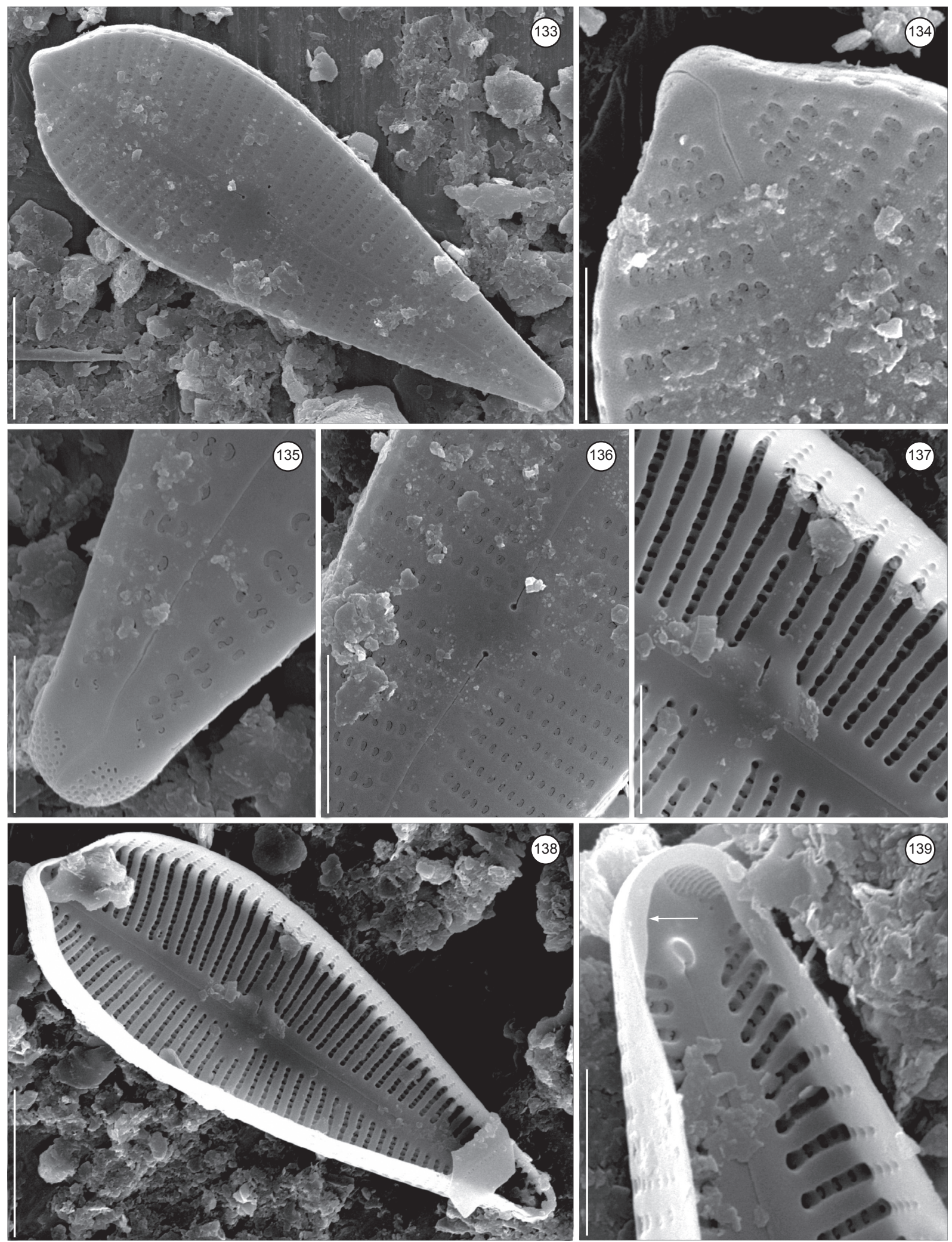

Figuras 133-139. Gomphonema turris var. coarctata, MEV. Figura 133: vista geral externa da valva. Escala: $10 \mu \mathrm{m}$. Figura 134: vista externa da extremidade distal da rafe no ápice da valva. Escala: $5 \mu \mathrm{m}$. Figura 135: detalhe do campo de poros basal. Escala: $5 \mu \mathrm{m}$. Figura 136: vista externa das extremidades proximais da rafe e abertura do estigma. Escala: $5 \mu \mathrm{m}$. Figura 137: área central interna mostrando as extremidades proximais da rafe e abertura do estigma. Escala: $5 \mu \mathrm{m}$. Figura 138: vista geral interna da valva. Escala: $10 \mu \mathrm{m}$. Figura 139: detalhe da helictoglossa e do pseudosepto (seta) na base da valva. Escala: $5 \mu \mathrm{m}$.

Figures 133-139. Gomphonema turris var. coarctata, SEM. Figure 133: external view of valve. Scale: $10 \mu \mathrm{m}$. Figure 134: external view of distal raphe ends in the valvar apex. Scale: $5 \mu \mathrm{m}$. Figure 135: detail of basal pores field. Scale: $5 \mu \mathrm{m}$. Figure 136: external view of proximal raphe ends and stigma opening. Scale: $5 \mu \mathrm{m}$. Figure 137: internal central area showing the proximal raphe ends and stigma opening. Scale: $5 \mu \mathrm{m}$. Figure 138: internal view of valve. Scale: $10 \mu \mathrm{m}$. Figure 139: detail of helictoglossa and pseudoseptum in the valvar base (arrow). Scale: $5 \mu \mathrm{m}$. 

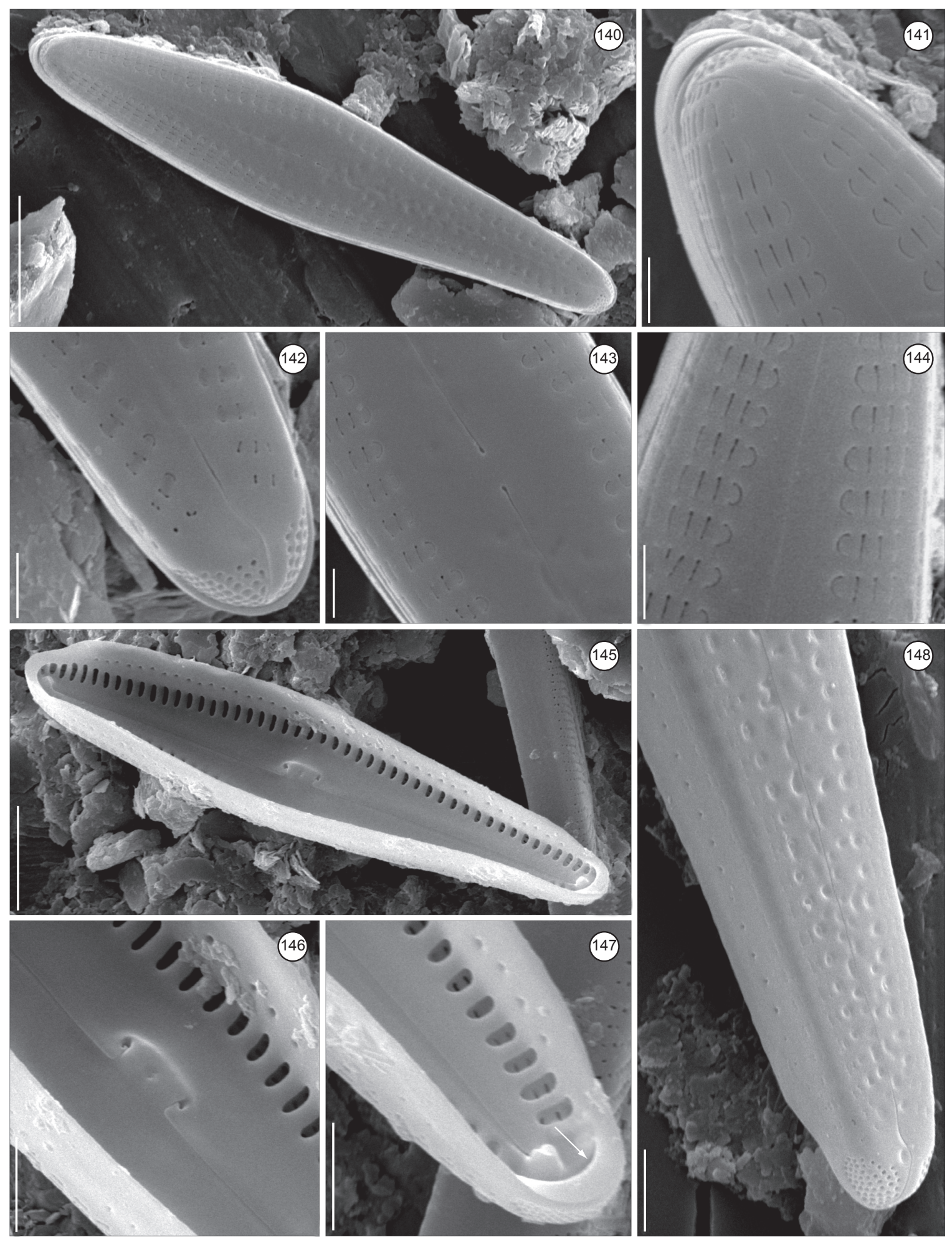

Figuras 140-148. Gomphonema sp.4, MEV. Figura 140: vista geral externa da valva. Escala: $5 \mu \mathrm{m}$. Figura 141: vista externa da extremidade distal da rafe no ápice da valva. Escala: $1 \mu \mathrm{m}$. Figura 142: campo de poros basal e extremidade distal da rafe. Escala: $1 \mu \mathrm{m}$. Figura 143: área central mostrando as extremidades proximais da rafe. Escala: $1 \mu \mathrm{m}$. Figura 144: detalhe da forma externa das aréolas. Escala: $1 \mu \mathrm{m}$. Figura 145: vista geral interna da valva. Escala: $5 \mu \mathrm{m}$. Figura 146: vista interna das extremidades proximais da rafe, abertura do estigma e estrias encurtadas. Escala: $2 \mu \mathrm{m}$. Figura 147: detalhe da helictoglossa e pseudosepto (seta) na base da valva. Escala: $2 \mu \mathrm{m}$. Figura 148: vista externa da valva mostrando a ornamentação da área axial da rafe e campo de poros basal. Escala: $2 \mu \mathrm{m}$.

Figures 140-148. Gomphonema sp.4, SEM. Figure 140: external view of valve. Scale: $5 \mu$ m. Figure 141: external view of distal raphe ends in the valvar apex. Scale: $1 \mu \mathrm{m}$. Figure 142: basal pores field and distal raphe ends. Scale: $1 \mu \mathrm{m}$. Figure 143: central area showing the proximal raphe ends. Scale: $1 \mu \mathrm{m}$. Figure 144: detail of external form of areolae. Scale: $1 \mu \mathrm{m}$. Figure 145: internal view of valve. Scale: $5 \mu \mathrm{m}$. Figure 146: internal view of proximal raphe ends, stigma opening and shortened striae. Scale: $2 \mu \mathrm{m}$. Figure 147: detail of helictoglossa and pseudoseptum in the valvar base (arrow). Scale: $2 \mu \mathrm{m}$. Figure 148 : external view of valve showing the ornamentation of axial area and basal pores field. Scale: $2 \mu \mathrm{m}$. 


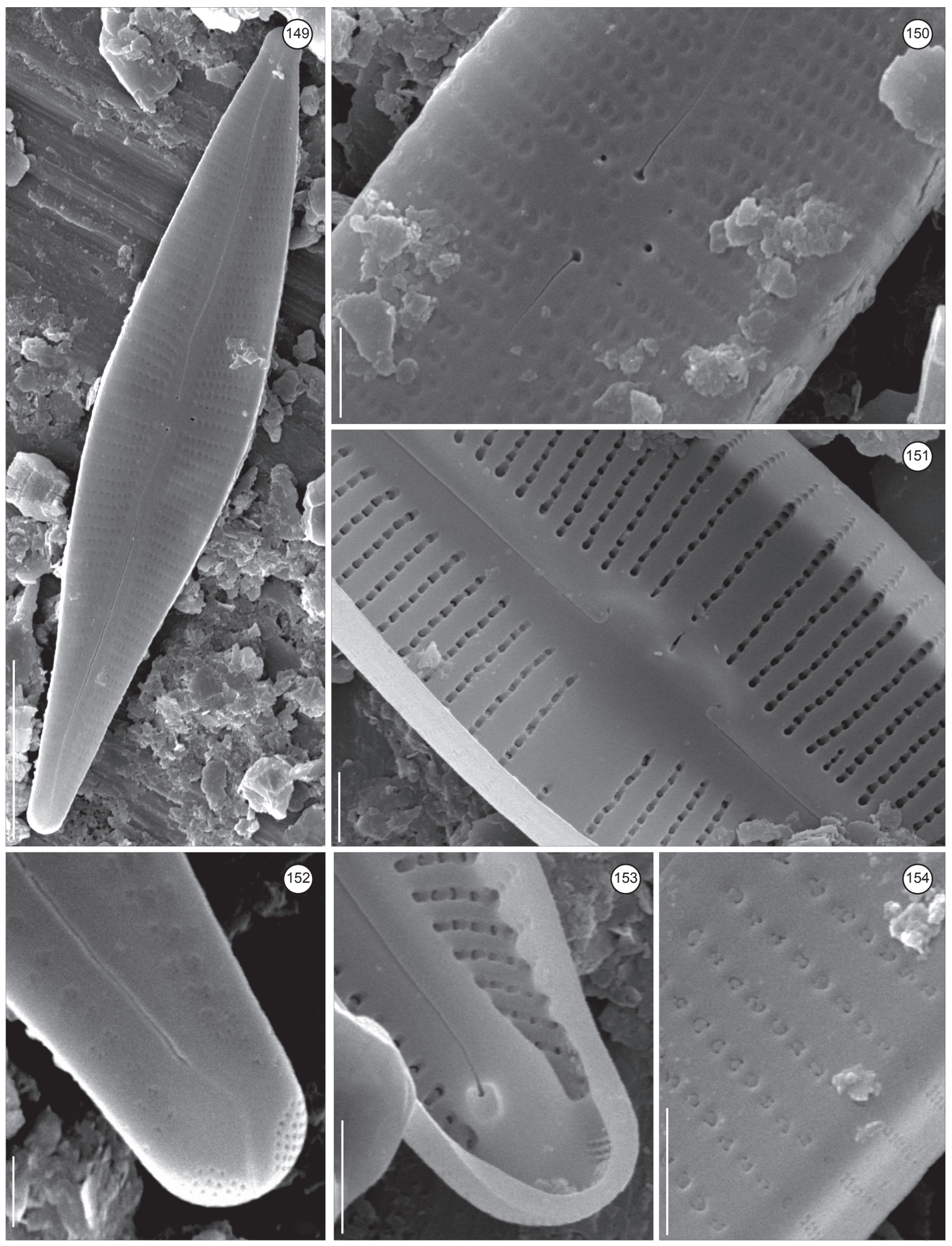

Figuras 149-154. Gomphonema sp.5, MEV. Figura 149: vista geral externa da valva. Escala: $10 \mu \mathrm{m}$. Figuras 150-151: área central mostrando extremidades proximais da rafe e abertura do estigma em vista externa e interna, respectivamente. Escala: $2 \mu \mathrm{m}$. Figura 152: detalhe externo do campo de poros basal. Escala: $2 \mu \mathrm{m}$. Figura 153: vista interna da base da valva mostrando helictoglossa, pseudosepto e proeminente nódulo distal. Escala: $2 \mu \mathrm{m}$. Figura 154: detalhe da forma externa das aréolas. Escala: $2 \mu \mathrm{m}$.

Figures 149-154. Gomphonema sp.5, SEM. Figure 149: external view of valve. Scale: $10 \mu \mathrm{m}$. Figures 150-151: central area showing the proximal raphe ends and stigma openingin external and internal view, respectively. Scale: $2 \mu \mathrm{m}$. Figure 152: detail of basal pores field in external view. Scale: $2 \mu \mathrm{m}$. Figure 153 : internal view of valvar base showing the helictoglossa, pseudoseptum and prominent distal nodule. Scale: $2 \mu \mathrm{m}$. Figure 154: note the external form of areolae. Scale: $2 \mu \mathrm{m}$. 
axial da rafe ornamentada por depressões levemente circulares na valva, rafe sinuosa com extremidades proximais externas dilatadas e internas fletidas em forma de gancho em direção ao estigma, extremidades distais finalizando em delicada helictoglossa situada em um proeminente nódulo terminal, helictoglossa levemente voltada para o lado oposto ao estigma, pseudosepto pouco espessado, campo de poros delicado, estrias formadas por aréolas ocluídas por complexa rota.

Comentário: Gomphonema sp.5 por vezes foi semelhante a formas maiores de G. gracile, entretanto as extremidades não são tão agudas e as estrias encontram-se fortemente radiadas nas extremidades. Contudo, a visualização de valvas de ambas as espécies em microscopia eletrônica de varredura permitiu constatar algumas diferenças. Gomphonema sp.5 possui nódulos terminais da rafe muito mais espessados que $G$. gracile e helictoglossa fletida para um dos lados da valva.

Também foi constatada semelhança com exemplares de G. lanceolatum Ehrenberg sensu Frickie ilustrados em A. Schmidt (1874-1959, pl. 236, Figura 34 e pl. 237, Figura 14). Entretanto houve dúvida quanto à determinação da espécie pela diferença na forma das extremidades valvares e da área central. Além disso, G. lanceolatum é de circunscrição confusa, havendo necessidade de uma revisão profunda do grupo. Diferentes formas taxonômicas são citadas na literatura como pertencentes a $G$. lanceolatum e a falta de uma caracterização mais precisa do tipo da espécie não permite uma comparação mais segura entre os táxons.

Material examinado: BRASIL. Paraná: Fazenda Rio Grande, Rio Maurício, perifíton em Egeria densa, VIII-IV-2006, Costin s.n. (UPCB58051); perifíton em Potamogeton polygonus, VIIIIV-2006, Costin s.n. (UPCB58052).

Citação para o Estado: primeiro registro para o Paraná.

20. Gomphosphenia grovei var. lingulata (Hustedt) Lange-Bertalot, Nova Hedwigia, 60(1-2):243, 1995.

Basiônimo: Gomphonema lingulatum Hustedt, Arch. Biol. 18, p.166, Figura 5:5, 1927.

Valvas clavadas com ápices arredondados e bases atenuadoarredondadas. Área axial lanceolada. Área central indistinta. Estigma ausente. Rafe reta com extremidades proximais dilatadas em poro. Estrias unisseriadas, paralelas a pouco radiadas, levemente mais espaçadas na região mediana e encurtadas regularmente por toda a extensão da valva. Aréolas inconspícuas. Compr.: $19 \mu \mathrm{m}$; larg.: $3 \mu \mathrm{m}, 22$ estrias em $10 \mu \mathrm{m}$.

Material examinado: BRASIL. Paraná: Fazenda Rio Grande, Rio Maurício, perifíton em Potamogeton polygonus, VIIIIV-2006, Costin s.n. (UPCB58052).

Obra consultada: Krammer \& Lange-Bertalot (1986).

Citação para o Estado: primeiro registro para o Paraná.

\section{Considerações Finais}

Dentre os 20 táxons identificados Gomphonema parvulum, G. lagenula, G. gracile, G. parallelistriatum e G. hawaiiense apresentaram ampla variação morfológica, permitindo uma análise métrica mais detalhada da população.

Gomphosphenia grovei var. lingulata é o primeiro registro do gênero para o estado e Gomphonema capitatum, G. contraturris, G. parallelistriatum, G. salae, G. sphaerophorum, G. turris var. coarctata, Gomphonema sp.1, Gomphonema sp.2, Gomphonema sp.3, Gomphonema sp.4 e Gomphonema sp.5 são citações pioneiras para o estado do Paraná.

\section{Agradecimentos}

Ao Centro de Microscopia Eletrônica da UFPR pela permissão de uso do microscópio eletrônico de varredura. À Dra. Maria Regina T. Boeger da UFPR pela identificação das macrófitas aquáticas. Ao CNPq e CAPES pelas bolsas de produtividade e pós-graduação.

\section{Referências Bibliográficas}

ANDREOLI, C.V., DALARMI, O., LARA, A.I., RODRIGUES, E.M. \& ANDREOLI, F.N. 1999. Os mananciais de abastecimento do sistema integrado da Região Metropolitana de Curitiba - RMC. Rev. Téc. Sanepar. 12(12): http://www.sanepar.com.br/sanepar/sanare/V12/Mananciais/ mananciais.html. (último acesso em 18/11/2008).

BARBER, H.G. \& HAWORTH, E.Y. 1981. A guide to the morphology of the diatom frustule. Freshwater Biological Association, Ambleside, Cumbria, p. 1-112. (Scientific Publications, n. 44).

BITTENCOURT-OLIVEIRA, M.C. 2002. A comunidade fitoplanctônica do rio Tibagi: uma abordagem preliminar de sua diversidade. In A bacia do rio Tibagi (M.E. Medri, E.Bianchini, O.A. Shibatta \& J.A. Pimenta, eds.) M.E. Medri, Londrina, p. 373-402.

CECY, I.I.T., VALENTE-MOREIRA, I.M. \& HOHMANN, E. 1976. Estudo ficológico e químico da água do tanque do Passeio Público de Curitiba, Estado do Paraná-Brasil. Bol. Mus. Bot. Mun. (25):1-37.

CETTO, J.M., LEANDRINI, J.A., FELISBERTO, S.A. \& RODRIGUES, L. 2004. Comunidade de algas perifíticas no reservatório do Irai, Estado do Paraná, Brasil. Acta Scient. 26(1):1-7.

Conselho Nacional do Meio Ambiente - CONAMA. 1986. Resolução n. 20 de 18 de Junho de 1986. Enquadramento dos corpos d'água doce, salina e salobra em função de seus usos. Diário Oficial da União, Poder Executivo, DF, 30 de Julho de 1986.

CONTIN, L.F. 1990. Contribuição ao estudo das diatomáceas, (Chrysophyta, Bacillariophyceae) na região de captação d'água do rio Iguaçu (SANEPAR), em Curitiba, Estado do Paraná, Brasil. Estud. Biol. (24):5-95.

COX, E.J. 1996. Identification of freshwater diatoms from live material. Chapman \& Hall, London, 158 p.

DÍAZ-CASTRO, J.G., SOUZA-MOSIMANN, R.M., LAUDARES-SILVA, R. \& FORSBERG, B.R. 2003. Composição da comunidade de diatomáceas perifíticas do Rio Jaú, Amazonas, Brasil. Acta Amaz. 33(4):583-606.

FRENGUELLI, J. 1933. Diatomeas de la región de de los esteros del Yberá. Ann. Mus. Nac. Hist. Nat. 37:65-476.

FRENGUELLI, J. 1941. Diatomeas del Río de La Plata, Argentina. Rev. Mus. La Plata, Sec. Bot. 15:213-334.

FÜRSTENBERGER, C.B. \& VALENTE-MOREIRA, I.M. 2000. Diatomáceas (Bacillariophyta) perifíticas da Lagoa Tarumã, Ponta Grossa, Paraná, Brasil. Insula. (29):117-134. (parte 1, Eunotiaceae).

HENDEY, N.I. 1964. An introductory account of the smaller algae of British coastal waters. Her Majesty's Stationery Office, London. (part V, Bacillariophyceae, Diatoms).

Instituto Ambiental do Paraná - IAP. 2005. Monitoramento da qualidade das águas dos rios da região metropolitana de Curitiba, no período de 2002 a 2005. IAP, Curitiba, 79 p.

KOCIOLEK, J.P. \& KINGSTON, J.C. 1999. Taxonomy, ultraestructure, and distribution of some gomphonemoid diatoms (Bacillariophyceae: Gomphonemataceae) from rivers in the United States. Can. J. Bot. 77(5):686-705.

KOCIOLEK, J.P. \& STOERMER, E.F. 1991. Taxonomy and ultrastructure of some Gomphonema and Gomphoneis taxa from the upper Laurentian Great Lakes. Can. J. Bot. 69:1557-1576.

KRAMMER, K. \& LANGE-BERTALOT, H. 1986. Bacillariophyceae: Naviculaceae. In Süßwasserflora von Mitteleuropa, Band 2/1 (H. Ettl, J. Gerloff, H. Heynig \& D. Mollenhauer, eds.). Gustav Fischer Verlag, Stuttgart.

KRAMMER, K. \& LANGE-BERTALOT, H. 1991. Bacillariophyceae: Achnanthaceae. Kritische Ergänzungen zu Navicula (Lineolatae) und Gomphonema. In (H. Ettl, G. Gärtner, J. Gerloff, H. Heynig, D. Mollenhauer, eds.). Süßwasserflora von Mitteleuropa. Gustav Fischer Verlag, Stuttgart, 437 p. (v. 2) 
LANGE-BERTALOT, H. 1993. 85 Neue Taxa und über 100 weitere neu definierte Taxa ergänzend zur Süßwasserflora von Mitteleuropa. Bibliot. Diatom. 27:1-454.

LANGE-BERTALOT, H. 1995. Gomphosphenia paradoxa nov. spec. et nov. gen. und Vorschlag zur Lösung taxonomischer Probleme infolge eines veränderten Gattungskonzepts von Gomphonema (Bacillariophyceae). Nov. Hedw. 1(1-2):241-252.

LANGE-BERTALOT, H., KÜLBST, K., LAUSER, T., NÖRPEL-SCHEMPP, M. \& WILLMANN, N. 1996. Documentation und revision der von George Krasske beschriebenen Diatomeen-taxa. Iconogr. Diatomol. 3:1-358.

LOBO, E.A., BES, D., TUDESQUE, L. \& ECTOR, L. 2004b. Water quality assessment of the Pardinho river, RS, Brazil, using epilithic diatom assemblages and faecal coliforms as biological indicators. Vie Milieu. 54(2/3):115-126.

LOBO, E.A, CALLEGARO, V.L.M, WETZEL, C.E., HERMANY, G. \& BES, D. 2004c. Water quality study of the Condor and Capivara streams, Porto Alegre municipal distric, RS, Brazil, using epilithic diatom biocenoses as bioindicators. Oceanol. Hydrobiol. Stud. 33(2):77-93.

LOBO, E.A., CALLEGARO, V.L.M., HERMANY, G., BES, D., WETZEL, C.E. \& OLIVEIRA, M.A. 2004a. Use of epilithic diatoms as bioindicators from lotic systems in southern Brazil with special emphasis on eutrophication. Acta Limnol. Bras. 16(1):25-40.

LOZOVEI, A.L. \& HOHMANN, E. 1977. Principais gêneros de microalgas em biótopos de larvas de mosquitos de Curitiba, Estado do Paraná, Brasil. Arq. Biol. Tecnol. 19(1-4):123-151. (parte III, Levantamento e constatação de ecologia).

LOZOVEI, A.L. \& LUZ, E. 1976. Diptera culicidae em Curitiba e arredores. Arq. Biol. Tecnol. 19(1):43-83. (parte II, Alimentação).

LOZOVEI, A.L. \& SHIRATA, M.T. 1990. Diatomáceas (Chrysophyta, Bacillariophyceae) no Rio Passaúna, Curitiba, Paraná, Brasil: levantamento qualitativo da diatomoflórula em um segmento do manancial. Estud. Biol. 27:5-56.

LUDWIG, T.A.V., BIGUNAS, P.I.T., NEIVA, T.F., COQUEMALA, V. \& PICCININI, C. 2005. Diatomáceas (Ochrophyta) dos lagos do Jardim Botânico, Curitiba, Paraná. In Anais da 10 Reunião Brasileira de Ficologia (R.C. Pereira, ed.). Museu Nacional, Rio de Janeiro, p. 301-324. (Série de livros do Museu Nacional, v. 10).

METZELTIN, D. \& LANGE-BERTALOT, H. 1998. Tropical Diatoms of South America. Iconogr. Diatomol. 5:1-220.

METZELTIN, D. \& LANGE-BERTALOT, H. 2007. Tropical Diatoms of South America II. Iconogr. Diatomol. 18:1-877.

METZELTIN, D., LANGE-BERTALOT, H. \& GARCIA-RODRÍGUES, F. 2005. Diatoms of Uruguay. Iconogr. Diatomol. 15:1-736.

MOREIRA-FILHO, H. \& MOMOLI, D.M. 1963. Diatomáceas no trato digestivo do Australorbis glabratus (Say, 1818). Bol. Univ. Fed. Paraná. (9):1-7. (Botânica)

MOREIRA-FILHO, H. \& MOMOLI, D.M. 1966. Diatomáceas em alguns focos larvários de anofelinos de Curitiba (Paraná, Brasil). Bol. Univ. Fed. Paraná. (15):1-6.(Botânica)

MOREIRA-FILHO, H. \& VALENTE-MOREIRA, I.M. 1981. Avaliação taxonômica e ecológica das diatomáceas (Bacillariophyceae) epífitas em algas pluricelulares obtidas nos litorais dos estados do Paraná, Santa Catarina e São Paulo. Bol. Mus. Bot. Mun. (47):1-17.

MOREIRA-FILHO, H., CECY, I.I.T. \& VALENTE-MOREIRA, I.M. 1976. Diatomáceas da Lagoa Dourada, Estado do Paraná, Brasil. Trib. Farm. 44(1-2):1-14

MOREIRA-FILHO, H., VALENTE-MOREIRA, I.M. \& CECY, I.I.T. 1973. Diatomáceas da barragem de captação d'água (SANEPAR) do rio Iguaçu, em Curitiba, estado do Paraná. Acta Biol. 2(1-4):133-145.

MORO, R.S. \& FÜRSTENBERGER, C.B. 1993. Diatomáceas (Bacillariophyceae) da lagoa Dourada (Parque Estadual de Vila Velha), Paraná, Brasil. Acta Biol. 22(1-4):15-30.

MORO, R.S., GARCIA, E. \& OLIVEIRA Jr., H.F. 1994. Diatomáceas (Bacillariophyceae) da represa Alagados, Ponta Grossa, Paraná, Brasil. Iheringia. (45):5-19.

MOURA, A.N. \& BITTENCOURT-OLIVEIRA, M.C. 2004. Diatoms (Bacillariophyceae) of the Tibagi river, southern Brazil. Algol. Stud. 112:73-87.
OLIVEIRA, M.A., TORGAN, L.C., LOBO, E.A. \& SCHWARZBOLD, A. 2001. Association of periphytic diatom species of artificial substrate in lotic environments in the Arroio Sampaio Basin, RS, Brazil: Relationships with abiotic variables. Braz. J. Biol. 61(4):523-540.

OLIVEIRA, M.A., TORGAN, L.C. \& RODRIGUES, S.C. 2002. Diatomáceas perifíticas dos Arroios Sampaio e Sampainho, Rio Grande do Sul, Brasil. Acta Bot. Bras. 16(2):151-160.

PATRICK, R. \& REIMER, C.W. 1975. The diatoms of the United States. Academy of Natural Sciences, Philadelphia. (v. 2, part 1, Monographs series n. 13).

Prefeitura do Município de Araucária. 2006. Relatório intermediário da leitura técnica. Araucária. http://www.araucaria.pr.gov.br/plano/ downloads/fase_2/relatorio_intermediaria_tecnica2.pdf (último acesso em 18/11/2008).

REICHARDT, E. 1995. Die Diatomeen (Bacillariophyceae). In Ehrenberg's Material von Cayenne, Guyana Gallica (H. Lange-Bertalot, ed.). Iconogr. Diatomol. 1:1-49.

REICHARDT, E. 1997. Taxonomische Revision des Artenkomplexes um Gomphonema pumilum (Bacillariophyceae). Nov. Hedw. 65(1-4):99-129.

REICHARDT, E. 1999. Zur Revision der Gattung Gomphonema. Iconogr. Diatomol. 8:1-203.

REICHARDT, E. 2001. Revision der Arten um Gomphonema truncatum und G. capitatum. In Studies on Diatoms (R. Jahn, J.P Kociolek, A. Witkowski, P. Compère, eds.). Koeltz Scientific Books, Koenigstein, p. 187-224.

REICHARDT, E. 2005. Die Identität von Gomphonema entolejum Østrup (Bacillariophyceae) sowie Revision ähnliche Arten mit weiter Axialarea. Nov. Hedw. 81(1-2):115-144

REICHARDT, E. 2007. Neue und wenig bekannte Gomphonema-Arten (Bacillariophyceae) mit Areolen in Doppelreihen. Nov. Hedw. 85(1-2):103-137.

REICHARDT, E. 2008. Gomphonema intermedium Hustedt sowie drei neue, ähnliche Arten. Diat. Res. 23(1):105-115.

REICHARDT, E. \& LANGE-BERTALOT, H. 1991. Taxonomische Revision des Artenkomplexes um Gomphonema angustum - G. dichotomum G. intricatum - G. vibrio und ähnliche Taxa (Bacillariophyceae). Nov. Hedw. 53(3-4):519-544

RODRIGUES, L. 1991. Naviculaceae (Bacillariophyceae) nas lagoas do horto florestal Dr. Luiz Teixeira Mendes, Município de Maringá, Paraná, Brasil. Rev. Unimar 13(12):273-298.

RODRIGUES, L. \& BICUDO, D.C. 2001. Similarity among periphyton algal communities in a lentic-lotic gradient of the upper Paraná river floodplain, Brazil. Rev. Bras. Bot. 24(3):235-248.

RODRIGUES, L.M. \& LOBO, E.A. 2000. Análise da estrutura de comunidades de diatomáceas epilíticas no arroio Sampaio, município de Mato Leitão, RS, Brasil. Cad. Pesq. 12(2):5-27. (série botânica).

ROUND, F.E., CRAWFORD, R.M. \& MANN, D.G. 1990. The Diatoms: biology and morphology of the Genera. University Press, Cambridge.

RUMRICH, U., LANGE-BERTALOT, H. \& RUMRICH, M. 2000. Diatoms of Andes. Iconogr. Diatomol. 9:1-673.

SALOMONI, S.E., ROCHA, O., CALLEGARO, V.L. \& LOBO, E.A. 2006. Epilithic diatoms as indicators of water quality in the Gravataí river, Rio Grande do Sul, Brazil. Hydrobiol. 559:233-246.

SCHMIDT, A. 1874-1959. Atlas der Diatomaceen-Kunde. Aschersleben \& Leipzig, Berlin.

SCHNECK, F., TOGAN, L.C. \& SCHWARZBOLD, A. 2008. Diatomáceas epilíticas em riacho de altitude no sul do Brasil. Rodriguésia. 59(2):325-338.

SIMONSEN, R. 1974. The diatom plankton of Indian Ocean Expedition of R/V "Meteor", 1964-65. Meteor Forsch. Ergebn. (D-Biol.). (19):1-66.

TAVARES, B. \& VALENTE-MOREIRA, I.M. 2000. Diatomoflórula do lago Cascavel, município de Cascavel, Estado do Paraná, Brasil. Hoehnea. 27(1):1-24. 